\title{
Two-moment bulk stratiform cloud microphysics in the GFDL AM3 GCM: description, evaluation, and sensitivity tests
}

\author{
M. Salzmann" ${ }^{1, *}$, Y. Ming ${ }^{2}$, J.-C. Golaz ${ }^{2}$, P. A. Ginoux ${ }^{2}$, H. Morrison ${ }^{3}$, A. Gettelman ${ }^{3}$, M. Krämer ${ }^{4}$, and L. J. Donner ${ }^{2}$ \\ ${ }^{1}$ Atmospheric and Oceanic Sciences Program, Princeton University, 300 Forrestal Road, Princeton, NJ 08544, USA \\ ${ }^{2}$ Geophysical Fluid Dynamics Laboratory, NOAA, P.O. Box 308, Princeton, NJ 08542, USA \\ ${ }^{3}$ National Center for Atmospheric Research, Boulder, Colorado, USA \\ ${ }^{4}$ Forschungszentrum Jülich GmbH, ICG-I, 52425 Jülich, Germany \\ *now at: Max Planck Institute for Meteorology, Bundesstraße 53, 20146 Hamburg, Germany
}

Received: 16 February 2010 - Published in Atmos. Chem. Phys. Discuss.: 8 March 2010

Revised: 29 July 2010 - Accepted: 9 August 2010 - Published: 30 August 2010

\begin{abstract}
A new stratiform cloud scheme including a twomoment bulk microphysics module, a cloud cover parameterization allowing ice supersaturation, and an ice nucleation parameterization has been implemented into the recently developed GFDL AM3 general circulation model (GCM) as part of an effort to treat aerosol-cloud-radiation interactions more realistically. Unlike the original scheme, the new scheme facilitates the study of cloud-ice-aerosol interactions via influences of dust and sulfate on ice nucleation. While liquid and cloud ice water path associated with stratiform clouds are similar for the new and the original scheme, column integrated droplet numbers and global frequency distributions (PDFs) of droplet effective radii differ significantly. This difference is in part due to a difference in the implementation of the Wegener-Bergeron-Findeisen (WBF) mechanism, which leads to a larger contribution from super-cooled droplets in the original scheme. Clouds are more likely to be either completely glaciated or liquid due to the WBF mechanism in the new scheme. Super-saturations over ice simulated with the new scheme are in qualitative agreement with observations, and PDFs of ice numbers and effective radii appear reasonable in the light of observations. Especially, the temperature dependence of ice numbers qualitatively agrees with in-situ observations. The global average long-wave cloud forcing decreases in comparison to the original scheme as expected when super-saturation over ice is allowed. Anthropogenic aerosols lead to a larger decrease in short-wave absorption (SWABS) in the new model setup, but outgoing
\end{abstract}

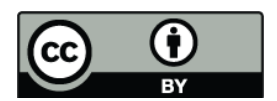

Correspondence to: M. Salzmann (marc.salzmann@zmaw.de) long-wave radiation (OLR) decreases as well, so that the net effect of including anthropogenic aerosols on the net radiation at the top of the atmosphere (netradTOA = SWABSOLR) is of similar magnitude for the new and the original scheme.

\section{Introduction}

Clouds are a major source of uncertainty in climate simulations (e.g. Soden and Held, 2006; IPCC, 2007). Cloudclimate feedbacks (mostly associated with optically thick low clouds) are known to be critical in determining the spread in climate sensitivity between models. Large uncertainties also exist regarding the effect of aerosols on cloud properties. Increasing (decreasing) cloud condensation nuclei (CCN) concentrations cause an increase (decrease) in cloud albedo (first indirect aerosol effect, Twomey, 1974). An increase in $\mathrm{CCN}$ has also been suggested to enhance cloud lifetimes and liquid water path by lowering the collision-coalescence rate (Albrecht, 1989). This can, however, to some extent be offset by the moistening due to the suppression of precipitation (leading to increasing liquid water content and subsequent rain formation) and increased entrainment of environmental air (Ackerman et al., 2004; Xue and Feingold, 2006; Jiang et al., 2006; Altaratz et al., 2008). The effect of increased entrainment with increasing $\mathrm{CCN}$ is at present not taken into account in limited-resolution global models.

Estimates reported by IPCC (2007) of the radiative forcing via the first indirect aerosol effect range from -1.8 to $-0.3 \mathrm{~W} \mathrm{~m}^{-2}$, compared to 1.66 (1.49 to 1.83$) \mathrm{W} \mathrm{m}^{-2}$ for anthropogenic carbon dioxide and 1.35 (1.00 to 1.90$) \mathrm{W} \mathrm{m}^{-2}$

Published by Copernicus Publications on behalf of the European Geosciences Union. 
for all other anthropogenic greenhouse gases including a small contribution from an increase in stratospheric water vapor due to increased methane oxidation. In the light of changing anthropogenic aerosol and aerosol precursor emissions and of the relatively short atmospheric residence time of aerosols (e.g. Andreae et al., 2005), cloud-aerosol interactions are a major research topic.

While many model studies have focused on liquid clouds, ice-aerosol interactions have only been considered recently in a few general circulation models (e.g. Lohmann and Kärcher, 2007; Lohmann et al., 2004; Lohmann and Diehl, 2006; Lohmann et al., 2007; Hoose et al., 2008b; Storelvmo et al., 2008; Liu et al., 2009), and the effects are even more uncertain than they are for liquid clouds. Ice crystals in the upper troposphere are an important absorber of infrared radiation. In addition, several mechanisms have been suggested by which a change in ice nuclei (IN) can influence mixedphase clouds (Lohmann, 2002; Hoose et al., 2008a). These effects could potentially outweigh the influences of IN on cirrus clouds (Lohmann and Feichter, 2005), but their magnitudes are still very uncertain. Furthermore, a recent study by Tsushima et al. (2006) suggests that the representation of mixed-phase clouds in climate models plays an important role for the response of clouds to carbon dioxide increase.

A prognostic treatment of ice particle numbers together with a two-moment bulk microphysics scheme (e.g. Lohmann et al., 2007; Morrison and Gettelman, 2008) allows for an improved coupling between aerosols and clouds. In particular, two-moment microphysics permits cloudy grid cells with different droplet number concentrations at identical liquid water content depending on $\mathrm{CCN}$ concentrations. This is essential for simulating processes which depend on droplet number concentration, such as collision-coalescence ("auto-conversion"). However, while two-moment bulk microphysics provides more physical realism than a single moment (mass only) bulk scheme, several significant uncertainties due to the description of individual microphysical processes remain (e.g. Morrison and Grabowski, 2007). Furthermore, while "homogeneous" ice nucleation (i.e. freezing of supercooled aqueous solutions at temperatures below $-35^{\circ} \mathrm{C}$; see Koop et al., 2000) is comparatively well understood, major uncertainties still exist regarding "heterogeneous" ice nucleation (i.e. various processes involving solid nuclei; see e.g. DeMott et al., 1997; Cziczo et al., 2004; Kärcher et al., 2007), which is the dominant ice nucleation pathway at temperatures above $-35^{\circ} \mathrm{C}$. Heterogeneous nucleation involving suitable IN requires a smaller supersaturation than homogeneous nucleation. Thus, the presence of a relatively small number of IN at low temperatures could, in principle, lead to a reduction in ice crystal number compared to a homogeneous nucleation scenario (e.g. DeMott et al., 1997; Kärcher et al., 2007).

In contemporary global models, additional uncertainties are due to the strong and often not well documented interactions of the microphysics parameterization with other pa- rameterizations such as the cloud cover and the moist convection parameterization. The cloud cover parameterization plays an important role in determining the in-cloud hydrometeor mixing ratios which in turn determine the rates of microphysical processes. Moist convection plays an important role for stratiform cloud microphysics through vapor transport and detrainment of liquid/ice (moistening), and through vapor/liquid/ice removal in precipitation (drying), and indirectly via influences on dynamics. A wealth of new observations from various platforms (e.g. Stephens et al., 2008; Krämer et al., 2009) are instrumental in addressing these uncertainties.

Here, we describe the implementation of the Morrison and Gettelman (2008) (MG08 hereafter) two-moment microphysics scheme into the GFDL Atmospheric Model version 3 (AM3) GCM in an effort to provide the framework for a more robust aerosol - cloud-ice coupling in the future. Currently, the GFDL AM3 GCM includes a prognostic treatment of droplet numbers based on Ming et al. (2006, 2007), but not of ice numbers. The base model, which is a simplified and therefore computationally less expensive version of the GFDL AM3 GCM is described in Sect. 2.1. The components of the new stratiform cloud scheme are described in Sects. 2.2.1 to 2.2.4. Differences in the implementation of the WBF process are discussed in Sect. 2.3. Results are presented and evaluated using satellite and in-situ observations in Sect. 3. The influence of the implementation of the WBF process on mixed-phase clouds is investigated in Sect. 4.1. Sensitivity to anthropogenic aerosols is investigated in Sect. 4.2. A list of symbols and acronyms is provided in Appendix B.

\section{Model description and setup}

\subsection{Brief description of the BASE model}

A simplified version of the recently developed GFDL AM3 GCM (Donner et al., 2010) is used in the present study. Unlike the standard version of this new model it does not include photochemistry and the number of vertical levels in the stratosphere is reduced. Sensitivity runs with an earlier prototype version of the model have indicated that the main results of this study do not critically depend on these simplifications.

The GFDL AM3 GCM has been developed from the GFDL AM2 GCM (GFDL Global Atmospheric Model Development Team, 2004, hereafter GAMDT04), but incorporates a large number of new features. A finite-volume dynamical core and a $48 \times 48 \times 6$ cube-sphere grid (projection of a cube onto the surface of a sphere, Putman and Lin, 2007) corresponding to a horizontal resolution of about $220 \times 220 \mathrm{~km}^{2}$ replace the finite difference dynamical core and the latitude-longitude horizontal grid used in the AM2 GCM. The number of vertical levels is increased from 24 to 
32 (48) with most additional levels in the upper troposphere (and stratosphere) in the simplified (standard) version. Deep convection is parameterized using the mass flux scheme of Donner (1993) and Donner et al. (2001) which includes a parameterization of the effects of anvils. Shallow convection is treated based on Bretherton et al. (2004). The PBL parameterization (based on Lock et al., 2000) and the radiative transfer algorithm are essentially unchanged from GAMDT04. Sulfate, dust, sea salt, black carbon (BC), organic carbon (OC), and secondary organic aerosols (SOA) formed from $\alpha$-pinene and n-butane are simulated on-line as in Magi et al. (2009). Sulfate is described by a single prognostic variable (i.e. a one-moment single-mode approach) while dust and sea-salt are simulated using five size bins each. The standard version of the model also includes gas phase chemistry based on Horowitz et al. (2003). Single scattering properties of liquid clouds are calculated following Slingo (1989) and the radiative properties of stratiform ice clouds are parameterized based on Fu and Liou (1993) as in GAMDT04. The effect of subgrid-scale cloud structure on radiation is represented using stochastically generated sub-columns based on Pincus et al. (2006). The stratiform cloud parameterization (subsequently referred to as "BASE" scheme), which is based on Tiedtke (1993), Rotstayn (1997), and Jakob and Klein (2000), is similar to GAMDT04, except that a prognostic equation for cloud droplet number has been incorporated into the AM3 GCM based on Ming et al. (2007). Aerosol activation is calculated based on the parameterization of Ming et al. (2006). Influences of sub-grid scale variations of vertical velocity on aerosol activation are parameterized by assuming a Gaussian distribution for the probability density function (PDF) of the vertical velocity $w$. Following an approach by Ghan et al. (1997) the maximum number of liquid droplets that can be activated is expressed as:

$N_{l, \text { act }}^{*}=\int_{0}^{\infty} N_{l, n}(w) \operatorname{pdf}(w) d w$,

where $N_{l, n}(w)$ is the number of droplets activated at velocity $w$. The width of the Gaussian distribution is related empirically to the mixing coefficients for heat $K_{T}$ (Golaz et al., 2010):

$\sigma_{w}=\max \left(\sqrt{\frac{2}{3}} K_{T}\left(c_{\mu}^{1 / 4} \Delta z\right)^{-1}, \sigma_{\min }\right)$

where $c_{\mu}=0.09$ (Rodi, 1993), $\sigma_{\min }=0.7 \mathrm{~m} \mathrm{~s}^{-1}$ for the BASE scheme, and $\Delta z(\mathrm{~m})$ is the vertical grid spacing. Equation (1) is integrated numerically using a 64-point Gauss-Hermite quadrature formula. The mixing coefficient for heat includes effects of boundary layer turbulence which is parameterized after Lock et al. (2000). Boundary layer turbulence is either thermally (buoyancy) or mechanically driven (wind shear). Sub-grid scale gravity waves are not parameterized explicitly in this approach. Although the effect of cloud top radiative cooling is parameterized in the Lock et al. PBL scheme, in practice, for $\sigma_{\min }=0.7 \mathrm{~m} \mathrm{~s}^{-1}$ the lower bound $\sigma_{\min }$ is effective in about $98 \%$ of all cases (Golaz et al., 2010), i.e. the parameterization behaves essentially as if the variance were fixed. In this case, $\sigma_{\min }$ can be interpreted as an average rather than a minimum standard deviation.

Following Ming et al. (2007), it is assumed that activation occurs only in the newly formed cloudy fraction of the grid box, so that the activation rate can be expressed as:

$\left.\frac{\partial N_{l}}{\partial t}\right|_{\text {act }}=N_{l, \text { act }}^{*} \frac{\partial C}{\partial t}$,

where $\partial C / \partial t$ is the rate of change of cloud cover from the Tiedtke (1993) parameterization. The formulation is based on the argument that condensation in pre-existing clouds is likely to add to the growth of existing droplets rather than activate additional CCN, i.e., that existing droplets suppress super-saturation. The removal of aerosols and trace gases by precipitation in the liquid and ice phase is parameterized as a first-order loss process and depends on prescribed speciesdependent in-cloud tracer fractions.

In the BASE run, the effective droplet radius $r_{\text {eff }}$ for stratiform clouds which is needed in the radiative transfer calculations is diagnosed from:

$r_{\mathrm{eff}}=k_{1} r_{v}=k_{1}\left(\frac{3 q_{l}^{\prime}}{4 \pi \rho_{w} N_{l}^{\prime}}\right)^{1 / 3}$

where $r_{v}$ is the volume mean radius, $k_{1}=1.143$ over land and $k_{1}=1.077$ over oceans is specified based on Martin et al. (1994), $q_{l}^{\prime}\left(\mathrm{kg} \mathrm{kg}^{-1}\right)$ is the in-cloud (liquid) droplet mixing ratio, $N_{l}^{\prime}\left(\mathrm{kg}^{-1}\right)$ is the in-cloud droplet number, and $\rho_{w}$ the density of water.

In order to adjust the model's radiation balance, the sedimentation velocity of ice particles in the original stratiform cloud scheme, which is estimated based on Heymsfield and Donner (1990), is increased by a factor 1.5 , thereby increasing outgoing long-wave radiation (OLR). The threshold radius for auto-conversion of liquid cloud droplets to rain, which mostly affects short-wave radiation, is set to $8.2 \mu \mathrm{m}$ in the BASE stratiform cloud scheme. The WBF process is parameterized based on Rotstayn et al. (2000).

Droplet activation is calculated in the shallow cumulus parameterization, but not in the deep convection parameterization. The deep convection parameterization contains a simple Kessler-type (Kessler, 1969) parameterization for representing microphysics in the updrafts (saturation adjustment, auto-conversion of cloud droplets to rain above a threshold mixing ratio, and accretion of cloud droplets by rain), while microphysical processes inside the anvils are not explicitly taken into account. Detrainment of cloud droplet number from deep convection is not taken into account in the BASE run. In the shallow convection parameterization, microphysics is represented by a simple saturation adjustment and instantaneous conversion of cloud droplets to rain 
above a threshold mixing ratio. Cloud liquid water and cloud ice mixing ratios in deep convective updrafts, deep convective anvils, and shallow cumuli are diagnosed separately and are taken into account in the radiative transfer calculations. In the shallow convection parametrization, droplet activation and detrainment are taken into account similar to Ming et al. (2007).

A detailed description and evaluation of the GFDL AM3 GCM is provided in Donner et al. (submitted manuscript). In the following, we describe the components of the newly added treatment of stratiform clouds and their implementation into the GFDL AM3 GCM (see overview in Table 1).

\subsection{Description of the NEW stratiform cloud scheme}

\subsubsection{The Morrison and Gettelman (2008) two-moment bulk microphysics parameterization}

The Morrison and Gettelman (2008) two-moment bulk microphysics scheme predicts the number concentrations and mixing ratios of cloud droplets and cloud ice, while snow and rain are treated diagnostically. The droplet size distribution is represented by gamma functions:

$N(D)=N_{0} D^{\mu} e^{-\lambda D}$,

where $D$ is the diameter, $N_{0}$ is the "intercept" parameter, $\lambda$ is the slope parameter, and $\mu=1 / \eta^{2}-1$ is the spectral shape parameter. The relative radius dispersion $\eta$ is computed as a function of the droplet number based on observations by Martin et al. (1994):

$\eta=0.0005714 N_{l}^{\prime \prime}+0.2714$,

where $N_{l}^{\prime \prime}$ is the in-cloud droplet number in units of $\mathrm{cm}^{-3}$. For cloud ice, a Marshall-Palmer size distribution is assumed in the current version of the scheme (equivalent to $\mu=0$ in Eq. 5). Parameterized processes include hydro-meteor collection, condensation/evaporation, freezing of cloud droplets and rain, melting, and sedimentation (Fig. 1). In-cloud subgrid variability of liquid cloud water mixing ratio is taken into account by assuming a PDF with fixed relative variance (i.e. variance divided by $q_{l}^{\prime 2}$, where $q_{l}^{\prime}$ is the in-cloud water mixing ratio; Morrison and Gettelman, 2008). Effective radii of droplets and cloud ice in the NEW run are obtained by dividing the third by the second moment of the size distribution given by Eq. (5):

$r_{\mathrm{eff}}=k_{2} r_{v}=\frac{\Gamma(\mu+4)}{2 \lambda \Gamma(\mu+3)}$

where $\Gamma$ is the Euler Gamma function. For liquid droplets, $k_{2}$ varies from about 1.07 for low $N_{l}^{\prime \prime}$ to about 1.27 for the upper limit $N_{l}^{\prime \prime}=535 \mathrm{~cm}^{-3}$. The WBF process is parameterized based on Rotstayn et al. (2000) as in the BASE scheme, but the implementations differ (see Sect 2.3). The MG08 scheme has recently also been implemented into the Community Atmosphere Model Version 3 (CAM3) as described in Gettelman et al. (2008). A detailed description of the scheme can be found in MG08.

In the present study, the minimum number-weighted mean cloud ice particle diameter is decreased from $10 \mu \mathrm{m}$ to $2 \mu \mathrm{m}$ and the threshold temperature below which all water is assumed to be frozen is decreased from $-35^{\circ} \mathrm{C}$ to $-40^{\circ} \mathrm{C}$. The maximum mean diameter for cloud ice $(400 \mu \mathrm{m})$ and the minimum $(2 \mu \mathrm{m})$ and maximum $(50 \mu \mathrm{m})$ mean diameter for cloud droplets are as in MG08. As in MG08, the use of a minimum diameter to adjust $N$ prevents inconsistencies between mixing ratio and number which can arise from the separate treatment of $N$ and $q$ and result in unrealistic mean particle size. A lower droplet number concentration limiter is not applied.

Homogeneous freezing of pre-existing liquid water droplets (now below $-40^{\circ} \mathrm{C}$ ) and immersion freezing of preexisting liquid water droplets (Bigg, 1953) are taken into account as in MG08 and at present are treated independently of IN concentration. In addition, in mixed-phase clouds with temperatures between -3 and $-40{ }^{\circ} \mathrm{C}$, contact freezing of pre-existing liquid water droplets through Brownian coagulation with dust particles is included in the NEW simulation similar to Liu et al. (2007), but using Eq. (2.6) of Meyers et al. (1992) to estimate the temperature dependence of the number of contact freezing nuclei. The total number of dust particles used in the parametrization of contact freezing is calculated as a sum of particle numbers over all five dust size bins (representing both hydrophilic (coated) and hydrophobic dust with radii between 0.1 and $10 \mu \mathrm{m}$ ). Ice nucleation, which in the case of "immersion nucleation" (see below) involves droplet formation and subsequent freezing within the same time step, but unlike "droplet freezing" does not act on pre-existing droplets is parameterized separately as described in Sect. 2.2.3.

Rain and snow are taken into account in the radiative transfer calculations based on very simple assumptions. Following Fu et al. (1995), rain and snow particles are assumed to be spherical and their single scattering properties only depend on their mass concentration. Except for the upgrade of the ice nucleation formulation from a temperature dependent formula in MG08 to the nucleation scheme based on Liu and Penner, 2005 as described in Sect. 2.2.3, the modifications described above do not have a major impact on the results of this study and will not be discussed further. Other, more fundamental changes in addition to the replacement of the ice nucleation parameterization are the coupling of the microphysics scheme to a modified version of the Tiedtke (1993) based Tompkins et al. (2007) cloud cover parameterization as described in the next section, the replacement of the Abdul-Razzak and Ghan (2000) liquid droplet activation formulation used in MG08 by the parameterization based on Ming et al. (2006, 2007), and a different treatment of subgrid scale variability of vertical velocity from the one used in MG08. Here, sub-grid variability of $w$ is parameterized 
Table 1. Overview of the stratiform cloud schemes in the "BASE" and the "NEW" run" 1 .

\begin{tabular}{lll}
\hline & BASE based on: & NEW based on: \\
\hline $\begin{array}{l}\text { cloud cover parameterization } \\
\text { microphysics module }\end{array}$ & Tiedtke $(1993)^{2}$ & Tompkins et al. (2007) \\
droplet activation $^{3}$ & Rotstayn $(1997)$, Jakob and Klein (2000) & Morrison and Gettelman (2008) \\
ice nucleation & Ming et al. (2006, 2007) & Ming et al. (2006, 2007) \\
& $\begin{array}{l}\text { Meyers et al. (1992), but only for } \\
\text { the WBF process }\end{array}$ & $\begin{array}{l}\text { Liu and Penner (2005) with dust IN, } \\
\text { modified Meyers formula, and } \\
\text { prognostic equation for ice number }\end{array}$ \\
\hline
\end{tabular}

\footnotetext{
${ }^{1}$ In addition, the impact of snow and rain on radiation (Sect. 2.2.1) and the detrainment of ice number (Sect. 2.2.4) are parameterized only in the NEW run.

2 As described in GFDL Global Atmospheric Model Development Team (2004).

${ }^{3}$ In the NEW run the minimum standard deviation of the sub-grid scale vertical velocity PDF ( $\left.\sigma_{\min }\right)$ in Eq. (2) is decreased from 0.7 to $0.3 \mathrm{~m} \mathrm{~s}{ }^{-1}$ for liquid droplet activation. Rotstayn et al. (2000).
}

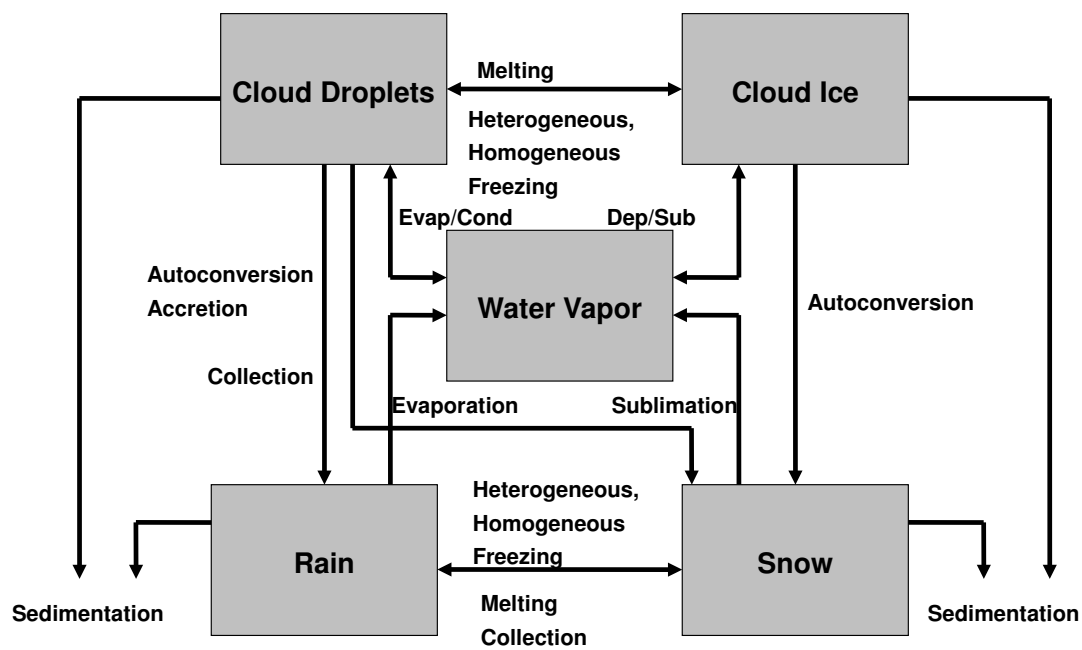

Fig. 1. Schematic: processes in the Morrison and Gettelman (2008) microphysics scheme (after Morrison et al., 2005).

using Eqs. (1) and (2), but the minimum standard deviation of the vertical velocity PDF in Eq. (2) is decreased from 0.7 in the BASE to $0.3 \mathrm{~m} \mathrm{~s}^{-1}$ in the NEW run, thereby increasing the top of the atmosphere net radiation flux (netradTOA) by more than $2 \mathrm{~W} \mathrm{~m}^{-1}$.

\subsubsection{Cloud cover scheme}

Since ice nucleation often requires high super-saturation with respect to ice (in excess of $40 \%$ to freeze deliquiscent sulfate aerosols in the upper troposphere), the original Tiedtke (1993) based cloud cover scheme has been modified to accomodate ice super-saturation following Tompkins et al. (2007). Assuming that the ice nucleation and subsequent deposition growth time-scales are short compared to the model time step, super-saturation is only permitted in the clear-sky portion of the grid box. Thus, the clear sky "environmental" vapor mixing ratio, $q_{e}$, is given by:
$q_{e}=\frac{q_{v}-C q_{s}}{1-C}$

where $q_{v}$ is the grid box mean prognostic water vapor mixing ratio, and $q_{s}$ is the saturation vapor mixing ratio with respect to liquid water for $T \geq 250 \mathrm{~K}$ and with respect to ice for $T<250 \mathrm{~K}$. The total cloud cover $C$ is defined as the sum of the stratiform and the diagnosed convective cloud cover, i.e. it is assumed that $q_{v}$ equals $q_{s}$ not only in stratiform, but also inside convective clouds, and that $q_{v}$ represents an average over the entire grid box, including the part that is covered by convective clouds. Unlike in the original Tiedtke (1993) scheme, $q_{e}$ is now allowed to exceed $q_{s}$.

If the change in saturation mixing ratio due to large scale vertical motion plus radiative and turbulent heating $\partial q_{s} /\left.\partial t\right|_{l s}<0$ and the grid box environmental relative humidity $\mathrm{RH}_{e} \geq K \times \mathrm{RH}_{c}$ (where $\mathrm{RH}_{e}=q_{e} / q_{s}, \mathrm{RH}_{c}$ is the critical 
relative humidity (see below), and $K$ is set to 0.8 above about $800 \mathrm{hPa}$ and increases toward one below), then the increase in cloud cover is given by (see Appendix A):

$$
\left.\frac{\partial C}{\partial t}\right|_{l s}=\left.\frac{-(1-C)}{2\left(\mathrm{RH}_{c} q_{s}-q_{e}\right)} \frac{\partial\left(\mathrm{RH}_{c} q_{s}\right)}{\partial t}\right|_{l s} .
$$

For $T \geq 250 \mathrm{~K}$ we take $q_{s}$ to be the saturation mixing ratio with respect to liquid water and set $\mathrm{RH}_{c}=1$ (similar to Tompkins et al., 2007). In the range 238.15-250 K, (where $q_{s}$ represents the saturation mixing ratio with respect to ice) $\mathrm{RH}_{c}$ is set to 1.2 , which is close to the nucleation threshold for some types of mineral dust and also close to the threshold for heterogeneous nucleation below $238.15 \mathrm{~K}$ in the Liu and Penner (2005) scheme (Eq. 14). Furthermore, this choice accounts for a fairly smooth transition of saturation vapor mixing ratio at $250 \mathrm{~K}$. There is, however, large uncertainty related to this choice and nucleation thresholds are likely to scatter over a large range of supersaturations depending on the composition and mixing state/chemical age of the dust aerosol. At present, hydrophobic and hydrophillic (coated) dust are combined into a single prognostic variable. Below $238.15 \mathrm{~K}\left(-35^{\circ} \mathrm{C}\right), \mathrm{RH}_{c}$ corresponds to the threshold relative humidity with respect to ice from the Liu and Penner (2005) scheme that is required for ice nucleation. Similarly rough choices are frequently made in cloud cover parameterizations.

The large scale condensation/deposition rate can be expressed as:

$$
\left.\frac{\partial\left(q_{l}+q_{i}\right)}{\partial t}\right|_{l s}=-\left.C \frac{\partial q_{s}}{\partial t}\right|_{l s}-\left.\left.\frac{\Delta t}{2} \frac{\partial C}{\partial t}\right|_{l s} \frac{\partial\left(\mathrm{RH}_{c} q_{s}\right)}{\partial t}\right|_{l s}
$$

where $q_{l}$ and $q_{i}$ are the mass mixing ratios of cloud liquid and cloud ice. The first term on the right hand side represents condensation in pre-existing clouds and the second term on the right hand side represents condensation associated with an increase in cloud fraction. The final phase partitioning of this rate is calculated taking into account the WBF process similar to Rotstayn et al. (2000), as described in MG08 (see also Sect. 2.3). Equations (9) and (10) differ from Tompkins et al. (2007) as discussed in Appendix A.

In order to guarantee that the in-cloud humidity does not exceed the saturation humidity at the end of the time step, the grid-mean humidity is limited by (Tompkins et al., 2007):

$q_{v}^{\max }=q_{s}\left\{C+(1-C) \mathrm{RH}_{c}\right\}$.

The corresponding clipping term has the effect of reducing the in-cloud humidity to the saturation value within one time step. Furthermore, if $q_{e} \geq q_{s}$ we do not allow evaporation, even if $\partial q_{s} /\left.\partial t\right|_{l s}>0$. Together with Eq. (11), this largely replaces the saturation adjustment that is performed after the microphysics calculations in the BASE stratiform cloud scheme.
In addition to evaporation due to $\partial q_{s} /\left.\partial t\right|_{l s}>0$, which is the "E1" term in the notation of Tiedtke (1993), "cloud erosion" (i.e. turbulent mixing with environmental air and subsequent evaporation) is assumed to take place if the grid box mean vapor mixing ratio is less than its saturation value. It is parameterized by applying the following tendencies to $C, q_{l}$, and $q_{i}$ :

$$
\left.\frac{\partial X}{\partial t}\right|_{e r}=-k_{e r} C X \frac{q_{s}-q_{v}}{q_{l}+q_{i}} .
$$

where $X$ stands for either $C, q_{l}$, or $q_{i}$, and $k_{e r}$ are the socalled "erosion coefficients" (see Sect. 2.4). Erosion is assumed to decrease the grid-box average cloud droplet number concentration by the same fraction as $q_{l}$. Evaporation due to large scale descent ("E1") is assumed to take place inside clouds and does not reduce the cloud droplet number concentration unless clouds evaporate completely.

Due to the assumption of rapid adjustment to saturation inside clouds, vapor deposition on ice does not have to be treated explicitly in the microphysics scheme. Furthermore, in order to be consistent with the parameterization assumption of rapid in-cloud adjustment, it is important that the formulations of microphysical processes do not depend on incloud supersaturation.

\subsubsection{Ice nucleation}

The number of ice crystals that can be formed by homogeneous nucleation and heterogeneous "immersion nucleation" at temperatures below $-35^{\circ} \mathrm{C}$ is determined based on the Liu and Penner (2005) parameterization, which has recently also been implemented into CAM3 (Liu et al., 2007). In addition to updraft velocity and temperature, the Liu and Penner (2005) parameterization takes into account aerosol number.

The threshold relative humidity with respect to liquid water for homogeneous ice nucleation is given by:

$\mathrm{RH}_{\mathrm{hom}}=a T_{c}^{2}+b T_{c}+c$,

where $a=6 \times 10^{-4} \ln w+6.6 \times 10^{-3}, b=6 \times 10^{-2} \ln w+$ 1.052, $c=1.68 \ln w+129.35$, and $T_{c}$ is the temperature in degree Celsius. This threshold is within $10 \%$ of the laboratory data of Koop et al. (1998) in the temperature range from $-35^{\circ} \mathrm{C}$ to $-60^{\circ} \mathrm{C}$ (Liu and Penner, 2005). In the original formulation of the Liu et al. scheme (Liu and Penner, 2005; Liu et al., 2007), immersion nucleation involves hydrophilic black carbon (BC) aerosol (i.e. BC aerosol internally mixed with soluble species such as soot coated by sulfate). In the present study, we assume dust particles to be potential immersion nuclei, but neglect the influence of black carbon, which is still very uncertain (see review of laboratory data by Kärcher et al., 2007). Since the Liu and Penner (2005) scheme is formulated for efficient ice nucleating aerosols, and independent of the composition of the immersion nuclei (X. Liu, personal communication, 2009), the threshold 
relative humidity over ice for immersion nucleation remains unchanged and is given by (Liu and Penner, 2005; Liu et al., 2009):

$\mathrm{RH}_{\text {het }}=0.0073 T_{c}^{2}+1.477 T_{c}+131.74$.

It lies in the range $120-130 \%$ for temperatures between -40 and $-80^{\circ} \mathrm{C}$. Above a critical number concentration of immersion nuclei given in Liu and Penner (2005); Liu et al. (2007), only heterogeneous nucleation takes place. The entire parameterization including expressions for the ice crystal numbers is described in Liu and Penner (2005) and in Liu et al. (2007). We apply Eqs. (7), (8), (10), and (11) of Liu et al. (2007) in addition to Eqs. (13) and (14) above. Equations (7), (8), and (11) of Liu et al. (2007) provide ice crystal number concentrations as functions of vertical velocity, temperature, and aerosol number concentration for homogeneous and heterogeneous nucleation, and Eq. (10) of Liu et al. (2007) specifies the critical IN concentration above which only heterogeneous nucleation is allowed to take place as function of vertical velocity and temperature (see Liu et al., 2007, for details). Beyond this critical IN concentration, water vapor is depleted efficiently by heterogeneous nucleation so that homogeneous nucleation does not occur.

In analogy to droplet activation (Ming et al., 2007), the ice nucleation rate is expressed as:

$$
\left.\frac{\partial N_{i}}{\partial t}\right|_{\mathrm{nuc}}=N_{i, \mathrm{nuc}}^{*} \frac{\partial C}{\partial t},
$$

where $N_{i, \text { nuc }}^{*}$ is the maximum number of ice crystals determined by the ice nucleation parameterization. Sub-grid scale variations of velocity are taken into account as in Eq. (1):

$N_{i, \text { act }}^{*}=\int_{0}^{\infty} N_{i, n}(w) \operatorname{pdf}(w) d w$,

but for ice nucleation, the minimum standard deviation $\sigma_{\min }$ is set to $0.25 \mathrm{~m} \mathrm{~s}^{-1}$, which is the standard deviation found for cirrus clouds by Kärcher and Ström (2003) based on INCA (Interhemispheric Differences in Cirrus Properties from Anthropogenic Emissions) measurements. This relatively large lower bound on $\sigma_{\min }$ takes into account that the effects of sub-grid scale gravity waves are not parameterized explicitly in the present version of the model.

At present, immersion nucleation is treated independently of droplet activation which is only calculated above the threshold temperature for homogeneous ice nucleation. Alternatively, droplet activation could in principle be calculated even at very low temperatures and could then be used to limit the number of newly formed ice particles due to immersion nucleation. Furthermore, the number of available IN is not reduced by immersion nucleation; instead IN removal is treated independently from immersion nucleation. For future model versions, a single more consistent framework for parameterizing droplet activation, (heterogeneous) nucleation, and aerosol removal would be desirable.
Since the AM3 GCM includes a one moment aerosol module with a single mode for sulfate, the sulfate aerosol number concentration is currently estimated based on mass assuming a log-normal size distribution with geometric mean diameter $D_{g, \text { dry }}=40 \mathrm{~nm}$ as in Barahona and Nenes (2008) and geometric dispersion is $\sigma_{g \text {,dry }}=2.0$. This diameter is lower than the one prescribed in the radiative transfer calculations $\left(D_{g, \text { dry }}=100 \mathrm{~nm}\right)$. Decreasing the $D_{g \text {,dry }}$ of sulfate was found necessary in order to simulate realistic ice number concentrations and possibly reflects the fact that sulfate aerosol nucleation in the cold upper troposphere is not represented in the model. For immersion nucleation involving dust, we multiply the total dust number from all five dust size bins by a factor 0.3 in order to roughly account for the fact that globally only about half of all dust is composed of efficient immersion nuclei (Hoose et al., 2008a; Diehl and Wurzler, 2004) and that only hydrophilic (chemically aged) dust should be considered as immersion nuclei, while the aerosol scheme only predicts the total amount of dust.

Deposition/condensation nucleation on mineral dust in the temperature range between $-5^{\circ}$ and $-35^{\circ} \mathrm{C}$ is currently represented by a modified version of the Meyers et al. (1992) formula. The modification roughly accounts for variations in simulated dust concentrations:

$N_{i, d}^{*}=\frac{\mathrm{DU}_{2.5}}{\mathrm{DU}_{2.5}^{*}} \exp \left(-0.639+12.96 S_{i}\right)$

where $N_{i, d}^{*}\left(1^{-1}\right)$ is the number of ice crystals due to deposition nucleation, $S_{i}=\mathrm{RH}_{e \text {,ice }}-1$ is the environmental supersaturation with respect to ice, $\mathrm{DU}_{2.5}$ is the simulated mass concentration of dust particles with diameter less than $2.5 \mu \mathrm{m}$, and $\mathrm{DU}_{2.5}^{*}$ is a prescribed surface dust concentration of $20 \mu \mathrm{g} \mathrm{m}^{-3}$. The modification is based on the observation that IN concentrations increase almost linearly with the concentration of large aerosol particles (Georgii and Kleinjung, 1967; Berezinskiy et al., 1986) and takes into account that the Meyers' formula is derived from surface observations. Equation (17) provides a rather crude estimate of nucleation on dust (comparable to scaling the Meyers' formula by a prescribed empirical decay rate of dust particle number concentrations with height; Liu et al., 2007), but has the advantage of including a dependence on simulated (height and location dependent) dust concentrations. It also takes into account the large difference between average Northern and Southern hemispheric dust concentrations (e.g. Minikin et al., 2003), which is neglected if a typical vertical dust profile is used to scale Meyer's formula. The number of newly formed ice particles in the empirical formulation Eq. (17) is, however, in principle allowed to exceed the simulated total number of dust particles available. Furthermore, it depends on environmental supersaturation in the clear portion of the grid box prior to the microphysics calculations, which is difficult to predict accurately in a model with a 30 min integration time step. At present $\mathrm{RH}_{e}$ can become unrealistically large in the 
presence of deep convection, but the excess water vapor is subsequently removed by (large-scale) condensation in the stratiform cloud parameterization.

\subsubsection{Detrainment from deep convection}

In the NEW run, the detrainment of droplet number from deep convection is computed from the detrained liquid water mass assuming a volume mean droplet radius of $10 \mu \mathrm{m}$. Detrainment of ice number from deep and shallow convection is calculated assuming hexagonal crystals. As in Kristjánsson et al. (2000), the mean maximum dimension $L_{m}$ is related to temperature based on measurements reported by Ryan (1996) and McFarquhar and Heymsfield (1996):

$L_{m}(\mu \mathrm{m})=1030.7 \exp (0.05522(\mathrm{~T}-279.5))$.

$L_{m}$ is limited to $T \geq-60^{\circ} \mathrm{C}$ corresponding to a minimum of $L_{m} \approx 26 \mu \mathrm{m}$. The aspect ratio $D / L_{m}$ is assumed to depend on $L_{m}$ as in Fu (1996). In the BASE run, detrainment of droplet number from deep convection is neglected, while droplet activation in shallow convection is taken into account in both runs.

\subsection{Implementation of the WBF process}

The WBF process is parametrized based on Rotstayn et al. (2000) in the BASE and in the NEW run, but the implementations differ. The central part of the Rotstayn et al. (2000) parameterization is a physically based calculation of the growth of cloud ice crystals by vapor deposition at the expense of coexisting cloud liquid water (see Rotstayn et al., 2000, for details). In the NEW scheme, for $-40^{\circ} \mathrm{C}<T_{c}<0^{\circ} \mathrm{C}$, the Rotstayn et al. (2000) approach is used to partition the combined large scale condensation/deposition rate $\left(\partial\left(q_{l}+q_{i}\right) /\left.\partial t\right|_{\text {strat }}\right.$ in Eq. A11) into a condensation $\left(\partial q_{l} /\left.\partial t\right|_{\text {strat }}\right)$ and a deposition $\left(\partial q_{i} /\left.\partial t\right|_{\text {strat }}\right)$ rate prior to integrating the microphysical rate equations (compare Eq. (7) of Morrison and Gettelman, 2008) as described in Sect. 3c of MG08, i.e. it is assumed that if the deposition rate is non-zero, newly formed condensate preferentially adds to deposition on ice. Then, if the ice deposition rate exceeds the rate of condensate formation, existing liquid droplets are assumed to evaporate and contribute to deposition growth as well (i.e. the WBF process). In the BASE scheme, on the other hand, above $-40^{\circ} \mathrm{C}$ all newly formed condensate is treated as a source term of liquid water in the integration of the $q_{l}$ equation. Furthermore, above $-40^{\circ} \mathrm{C}$, all newly formed condensate adds to an intermediate liquid water mixing ratio $q_{l, m}$. This intermediate liquid water mixing ratio is used in several places in the integration of the $q_{l}$ equation, among others to calculate the auto-conversion rate and in a unit conversion affecting the deposition rate. Numerically, the $q_{l}$ and $q_{i}$ rate equations are integrated as described in Morrison and Gettelman (2008) in the NEW run and as described in Tiedtke (1993) in the BASE run. Additional aspects of the implementation of the WBF process such as as- sumptions regarding spatial inhomogeneity in mixed-phase clouds are discussed in Sect. 3.6.

\subsection{Simulation setup}

The results in the next section are based on two five-year integrations in which monthly mean sea-surface temperatures have been prescribed based on the Hadley Centre Sea Ice and Sea-Surface Temperature data set (HadISST1, Rayner et al., 2003) for the period from January 2000 to December 2004 after a one year initial spin-up. Additional sensitivity runs are described in Sect. 4. Anthropogenic emissions of $\mathrm{SO}_{2}$, $\mathrm{OC}, \mathrm{BC}$, and SOA precursors are specified based on estimates prepared by Lamarque et al. (2009) in support of the IPCC AR5 and are kept fixed at the estimate for the year 2000. Biogenic emissions are as described in Magi et al. (2009). Dust and sea salt sources are computed on-line and depend on meteorological conditions. Sulfur emissions from non-explosive "background" volcanoes are set to 0.25 times the values of Andres and Kasgnoc (1998) as in Donner et al. (2010). For $\mathrm{SO}_{2}$, sulfate, dimethyl sulfide (DMS), and $\mathrm{H}_{2} \mathrm{O}_{2}$, prognostic equations are solved, while climatological monthly mean concentrations of $\mathrm{OH}, \mathrm{HO}_{2}, \mathrm{O}_{3}$, and $\mathrm{NO}_{3}$ as well as $\mathrm{pH}$ and the photolysis rate coefficient $j\left(\mathrm{H}_{2} \mathrm{O}_{2}\right)$ are prescribed based on results from a simulation for the years 1980-2000 in which a fairly comprehensive photo-chemistry (based on Horowitz et al., 2003) was included in the AM3 GCM.

Scavenging coefficients of trace gases and aerosols (identical for ice and liquid clouds) as well as cloud erosion coefficients are identical in the BASE and the NEW run, while $\sigma_{\min }$ has been decreased as described in Sect. 2.2.1. The fraction $f_{\text {adi }}$ of ice detrained from anvils in the deep convection parameterization has been decreased from 5\% to $3 \%$ in the NEW run in order to decrease an OLR bias in the tropics (see Sect. 3.8). The erosion coefficients in the simplified 32-level version are set to $5 \times 10^{-6} \mathrm{~s}^{-2}$ under turbulent conditions (i.e. where the eddy diffusion coefficient for temperature $\left.K_{T} \geq 0.1 \mathrm{~m}^{2} \mathrm{~s}^{-1}\right), 8 \times 10^{-6} \mathrm{~s}^{-1}$ under non-turbulent convective conditions (i.e. where $K_{T}<0.1 \mathrm{~m}^{2} \mathrm{~s}^{-1}$ and the convective mass flux $M_{c}>1 \times 10^{-3} \mathrm{~kg} \mathrm{~m}^{-2} \mathrm{~s}^{-1}$ ), and to $1 \times 10^{-6} \mathrm{~s}^{-1}$ elsewhere, resulting in a net radiation flux at the top of the atmosphere that is that is fairly close to the one in the standard 48 level version of the model. Except for deep convective conditions, these values are identical to GFDL Global Atmospheric Model Development Team (2004), but they differ from the 48-level version including chemistry (Donner et al., submitted manuscript). Sensitivity runs with an earlier prototype version of the model have indicated that the microphysical properties of the simulated clouds which are the focus of the present paper do not critically depend on whether the simplified 32-level or the full 48-level version of the model is used. 


\section{Results and model evaluation}

\subsection{Annual global and zonal mean diagnostics}

An overview of various global annual mean diagnostics is provided in Table 2 and zonal mean diagnostics are shown in Figs. 2 and 3. The global mean aerosol optical depth (AOD) compares well with estimates based on MODIS and the zonal mean structure is also well captured (Fig. 2a). The AOD in tropical biomass burning regions is slightly over-estimated in the BASE run while a local maximum in the southern mid-latitudes, where sea-salt (dashed line in Fig. 2a) is an important contributor to total aerosol, is reproduced. Zonal mean AOD from the BASE and the NEW run agree well with each other considering that identical scavenging coefficients have been applied with different stratiform cloud schemes. The global average surface precipitation $\left(P_{\text {tot }}\right)$ and the zonal mean structure (Fig. 2b) are also very similar in the BASE and the NEW run. $P_{\text {tot }}$ is higher than the observation based estimate in both runs. The contribution from the stratiform cloud scheme $P_{\text {strat }}$ decreases by $24 \%$ in the NEW run compared to the BASE run, while the contribution from convective clouds $\left(P_{\text {conv }}=P_{\text {tot }}-P_{\text {strat }}\right)$ increases.

Satellite retrieved liquid water path (LWP) is subject to large uncertainty and the range of observations from various satellites is larger than suggested by the range in Table 2, which is solely based on SSM/I data. The LWP due to cloud droplets in stratiform and convective clouds $\left(\mathrm{LWP}_{\mathrm{cw}}\right)$ over oceans is similar in both runs and is lower than the SSM/I retrievals. It is also lower than the LWP in many other global model studies (see e.g. Li et al., 2008).

Total liquid water path $\left(\mathrm{LWP}_{\text {tot }}\right)$ and total ice water path $\left(\mathrm{IWP}_{\text {tot }}\right)$ from the BASE and the NEW run are not directly comparable to each other since the differences in simulated $\mathrm{LWP}_{\text {tot }}$ and $\mathrm{IWP}_{\text {tot }}$ are mainly due to the inclusion of rain and snow in the NEW run, which are not carried as separate diagnostic variables in the BASE run. The stratiform and convective contributions to $\mathrm{LWP}_{\text {tot }}$ and $\mathrm{IWP}_{\text {tot }}$ are comparable and of similar magnitude in both runs and their zonal mean structure is similar as well (solid lines in Fig. 2c and red solid vs. blue dashed line in Fig. 2e). The Rotstayn (1997) microphysics scheme used in the BASE run combines cloud ice as well as snow and graupel into one prognostic variable, but in addition to this some of the sedimenting ice hydrometeors are only counted as surface precipitation. In reality, a fraction of the latter would also still be suspended during the time step, and should be included in an IWP diagnostic that is comparable to CloudSat observations. However, since it is not straight forward to diagnose the suspended fraction, we have decided to exclude it from the present analysis.

A large fraction of the total simulated IWP originates from convective clouds (especially deep convective anvils, not shown), and zonal mean IWP in the tropics is overestimated relative to IWP from CloudSat (compare solid lines in Fig. $2 \mathrm{f}$ to solid lines in Fig. 2e). Taking this into account, the
Table 2. Global annual mean model results and observations: Aerosol optical depth (AOD) estimates based on MODIS (Remer et al., 2008), surface precipitation $\left(P_{\text {tot }}\right)$ based on GPCPv2 (Adler et al., 2003), liquid water path (LWP) over ocean based on SSM/I (Greenwald et al., 1993; Weng and Grody, 1994), ice water path (IWP) based on CloudSat (Austin et al., 2009), total cloud cover (TCC) based on ISCCP (Rossow and Schiffer, 1999) and surface observations (Warren et al., 1986, 1988), short wave cloud forcing (SWCF) and longwave cloud forcing (LWCF) ranges based on various satellite products compiled by Loeb et al. (2009) and for LWCF also on TOVS retrievals Susskind et al. (1997); Scott et al. (1999) cited from Lohmann et al. (2007). $N_{l C}^{\prime}=\int_{z}\left(\rho N_{l}^{\prime}\right) d z$ is the columnintegrated in-cloud droplet number.

\begin{tabular}{|c|c|c|c|}
\hline Simulation & BASE & NEW & OBS \\
\hline AOD ocean & 0.14 & 0.13 & $0.13-0.14$ \\
\hline AOD land & 0.17 & 0.16 & 0.19 \\
\hline$P_{\text {tot }}\left(\mathrm{mm} \mathrm{d}^{-2}\right)$ & 3.05 & 3.04 & 2.61 \\
\hline$P_{\text {strat }}\left(\mathrm{mm} \mathrm{d}^{-2}\right)$ & 1.14 & 0.87 & \\
\hline $\mathrm{LWP}_{\mathrm{cW}}^{1}$ ocean $\left(\mathrm{g} \mathrm{m}^{-2}\right)$ & 56.6 & 51.3 & $63-81$ \\
\hline $\mathrm{LWP}_{\text {tot }}\left(\mathrm{g} \mathrm{m}^{-2}\right)$ & 51.3 & 62.2 & \\
\hline droplets stratiform & 41.6 & 38.3 & \\
\hline rain stratiform & - & 13.6 & \\
\hline droplets convective & 9.76 & 10.3 & \\
\hline $\operatorname{IWP}_{\text {tot }}\left(\mathrm{g} \mathrm{m}^{-2}\right)$ & 70.3 & 107.8 & $75 \pm 30$ \\
\hline cloud ice stratiform & 29.0 & 30.4 & \\
\hline snow stratiform & - & 37.0 & \\
\hline cloud ice convective & 41.3 & 40.4 & \\
\hline $\operatorname{TCC}(\%)$ & 69.9 & 65.7 & $62-68$ \\
\hline $\operatorname{SWCF}\left(\mathrm{W} \mathrm{m}^{-2}\right)$ & -51.0 & -50.1 & -46 to -53 \\
\hline $\operatorname{LWCF}\left(\mathrm{W} \mathrm{m}^{-2}\right)$ & 26.4 & 24.3 & $22-31$ \\
\hline netradTOA $\left(\mathrm{W} \mathrm{m}^{-2}\right)$ & 1.2 & 0.9 & \\
\hline$N_{l C}^{\prime}\left(10^{10} \mathrm{~m}^{-2}\right)$ & 4.6 & 2.1 & \\
\hline
\end{tabular}

${ }^{1} \mathrm{LWP}_{\mathrm{cW}}$ includes stratiform and convective cloud droplets, but not rain.

global mean IWP in the NEW run is on the upper end of the fairly wide uncertainty range from CloudSat $\left(45-105 \mathrm{~g} \mathrm{~m}^{-2}\right)$. Since SSM/I derived LWP are problematic in the case of precipitating clouds, it is not uncommon to neglect rain water when comparing SSM/I retrieved LWP to simulated LWP. In the case of CloudSat IWC, on the other hand, it is understood that "ice" represents all frozen hydrometeors including snow and graupel (Waliser et al., 2009). Including a separate snow diagnostic in the comparison of zonal mean IWP in Fig. $2 \mathrm{f}$ would certainly improve the agreement of the BASE run with CloudSat at mid and high latitudes.

The total cloud cover (Fig. 3b) decreases from 69.9 to $65.7 \%$ in the NEW run, which is in the range of observations cited in Table 2. A large difference between the BASE and the NEW run is found in the zonal mean column integrated in-cloud droplet number $N_{l C}^{\prime}=\int_{z}\left(\rho N_{l} / C\right) d z$ (Fig. 3a) at high and mid latitudes. This is also reflected in the global mean $N_{l C}^{\prime}$ in Table 2 . If, however, only grid points where $T>-15^{\circ} \mathrm{C}$ are taken into account in the analysis (dashed line 

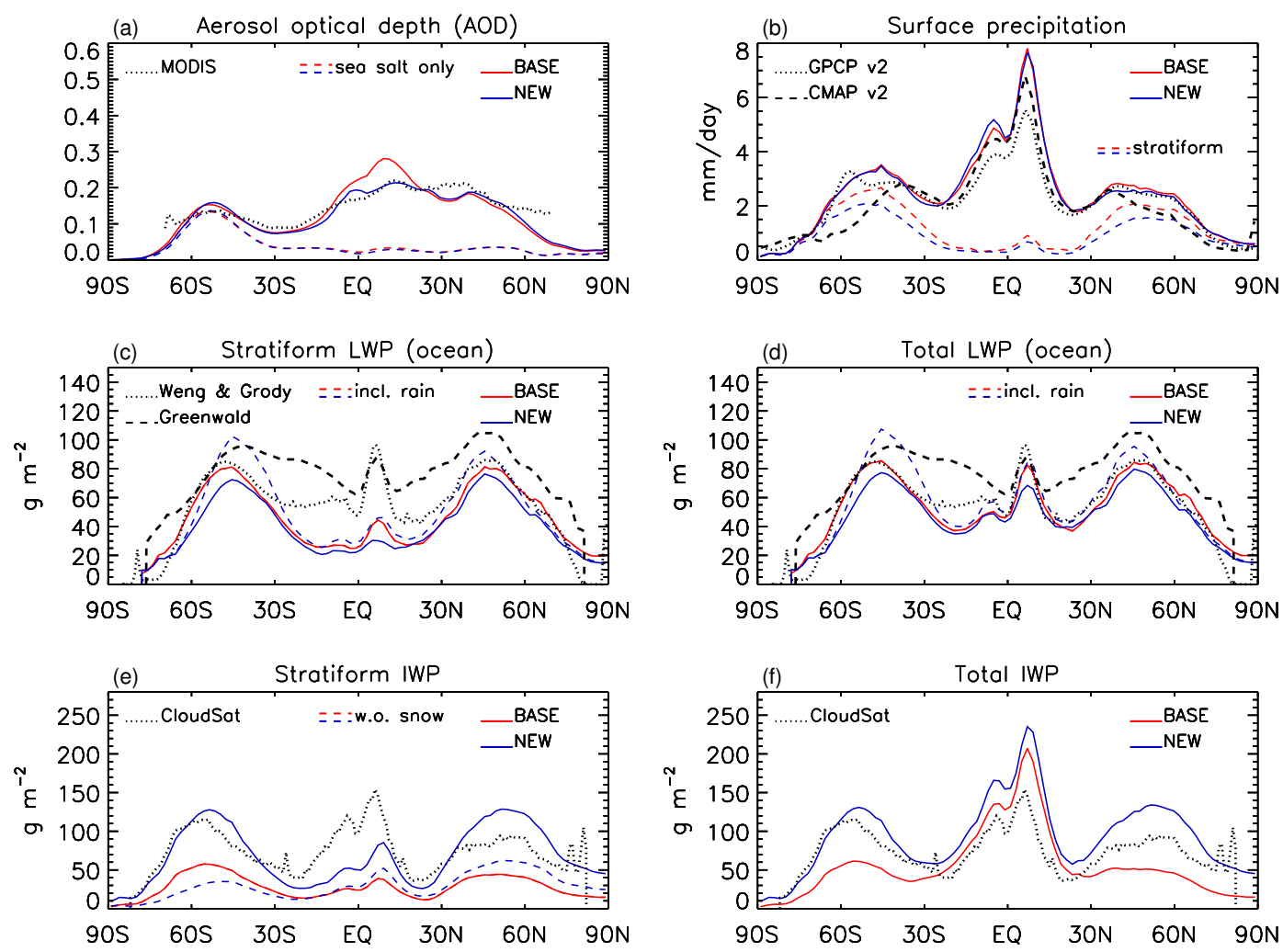

Fig. 2. Zonal mean model results and observations (see caption to Table 2). Dashed lines in (a) are simulated AOD due to sea-salt only for the BASE (red) and the NEW run (blue); (b) includes an additional precipitation estimate from CMAP (Xie and Arkin, 1997) Version 2. Dashed lines in (b) denote contributions from the stratiform cloud scheme. Total LWP and IWP in (d) and (f) include contributions from convective clouds. Snow is diagnosed separately only in the NEW scheme. The dashed blue line in (e) does not include contributions from snow, while the solid blue lines in (e) and (f) do.
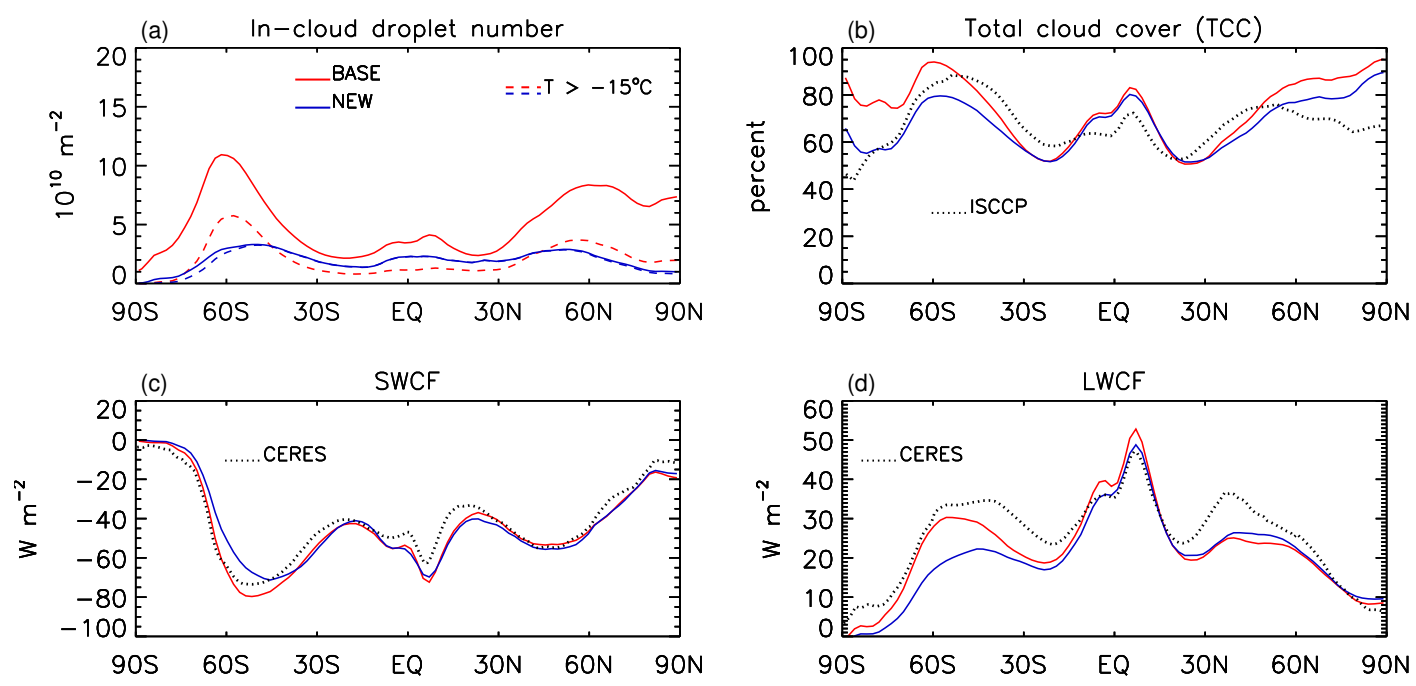

Fig. 3. As Fig. 2. Column integrated zonal mean in-cloud droplet numbers in (a) are for the entire vertical domain (solid lines) and for temperatures above $-15^{\circ} \mathrm{C}$ only (dashed lines). 

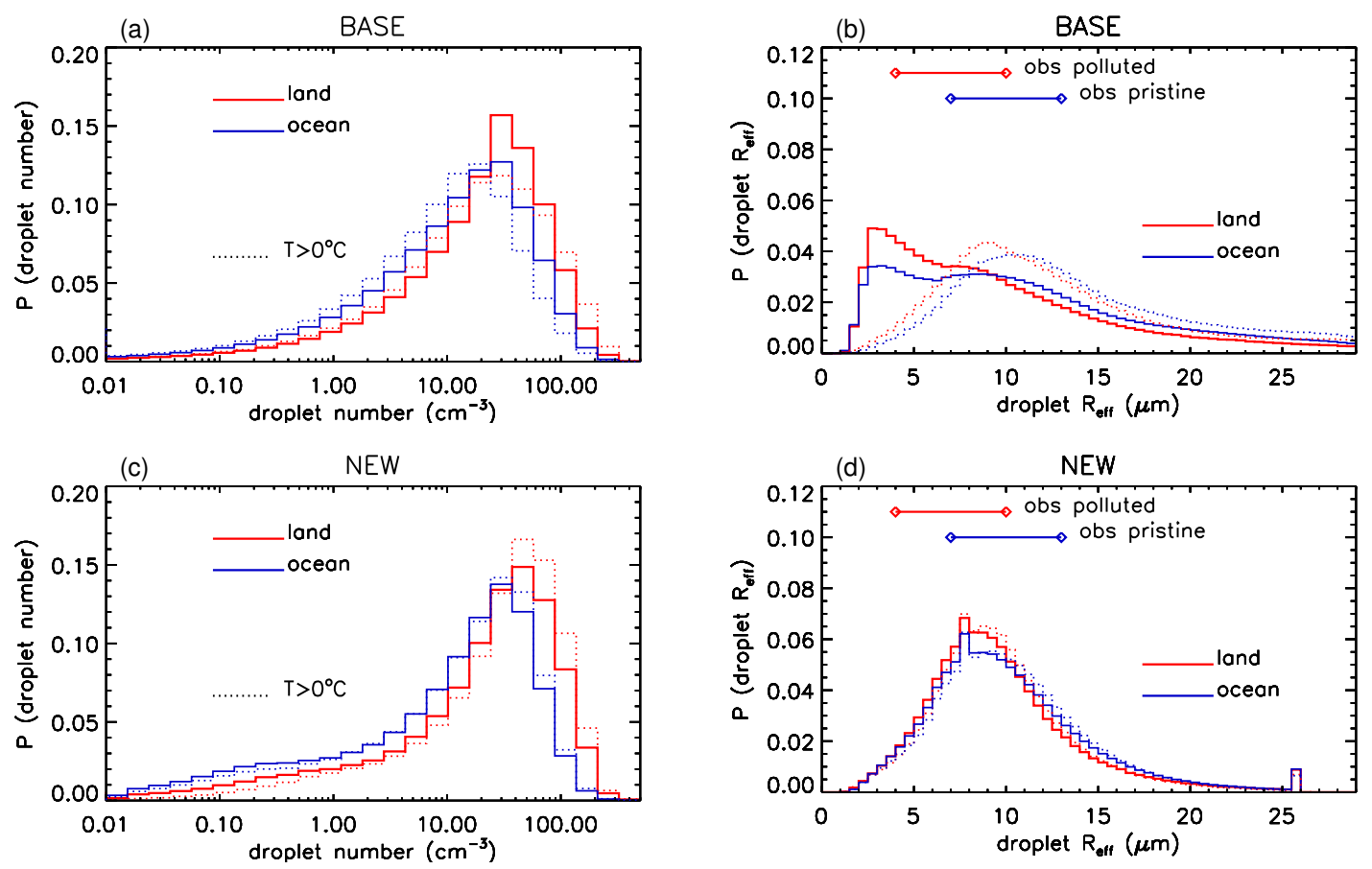

Fig. 4. Global PDFs of in-cloud droplet number and droplet effective radius over land and over oceans for clouds with liquid water content above $10^{-6} \mathrm{~kg} \mathrm{~m}^{-3}$. Ranges of effective droplet radii from observations (lines and diamonds) under pristine (7-13 $\left.\mu \mathrm{m}\right)$, and polluted (4$10 \mu \mathrm{m})$ conditions are taken from Gettelman et al. (2008) and are based on Bower and Choularton (1992), Martin et al. (1994), Brenguier et al. (2003), and Pawlowska et al. (2006). Dotted lines represent the PDFs for grid-points where $T>0{ }^{\circ} \mathrm{C}$. The model sampling frequency is $247 \mathrm{~h}$.

in Fig. 3a), the difference decreases significantly. This indicates a significantly larger abundance of supercooled droplets in the BASE run. In Sect. 4.1, it is suggested that this difference can be explained by a difference in the implementation of the WBF process between the two stratiform cloud schemes. A maximum in zonal mean column-integrated incloud droplet number over the southern ocean is simulated in the BASE run, but not the NEW run.

The global mean short-wave cloud forcing (SWCF) is similar in both runs and lies within the range of uncertainty from observations. Multi-year global average long-wave cloud forcing (LWCF) derived from ERBE and CERES are in the range of 27-31 $\mathrm{W} \mathrm{m}^{-2}$ (Loeb et al., 2009), while the LWCF derived from TOVS retrievals is only $22 \mathrm{Wm}^{-2}$ (Table 2, cited from Lohmann et al., 2007). The ISCCP FD dataset Zhang et al. (2004) yields a global LWCF of $26.5 \mathrm{~W} \mathrm{~m}^{-2}$ for the period from March 2000 through February 2005 (cited from Loeb et al., 2009), which is similar to the LWCF in the BASE run. The LWCF in the NEW run is $\sim 2 \mathrm{~W} \mathrm{~m}^{-2}$ lower than in the BASE run, but still above the TOVS based estimate. The net radiation flux at the TOA (netradTOA) is $0.9 \mathrm{~W} \mathrm{~m}^{-2}$ in the NEW and $1.2 \mathrm{~W} \mathrm{~m}^{-2}$ in the BASE run.

\subsection{Cloud liquid number and size PDFs}

Figure 4 shows the probability density function (PDF) of incloud liquid droplet number $\left(N_{l}^{\prime}\right)$ and droplet effective radius $\left(r_{\text {eff }}\right)$ over land and over oceans from the BASE and the NEW run. Especially the PDFs of $r_{\text {eff }}$ differ significantly between the BASE and the NEW run. Low effective radii in the range of 2 to $5 \mu \mathrm{m}$ are more common in the BASE run than in the NEW run if super-cooled cloud droplets at temperatures below $0{ }^{\circ} \mathrm{C}$ are taken into account (compare also Fig. 3a). If only temperatures above $0^{\circ} \mathrm{C}$ are taken into account, the PDFs of $r_{\text {eff }}$ yield a more similar shape (dotted lines in Fig. 4b and d), but the variance in the NEW run is significantly lower. This is also the case when $\sigma_{\min }$ in Eq. (2) is not decreased in the NEW run (not shown). Although different formulas are used to diagnose $r_{\text {eff }}$, the difference between $k_{1}$ in Eq. (4) and $k_{2}$ in Eq. (7) is too small to explain this difference in variance. It is more likely that the lower variance in the NEW run is due to the different representation of microphysical processes acting on droplet number, especially the auto-conversion parameterization. The Manton and Cotton (1977) auto-conversion parameterization, which is used in the BASE run, requires a certain droplet numberdependent threshold of $q_{l}^{\prime}$ to be reached before the conversion of cloud droplets to rain commences. Conversely, for 

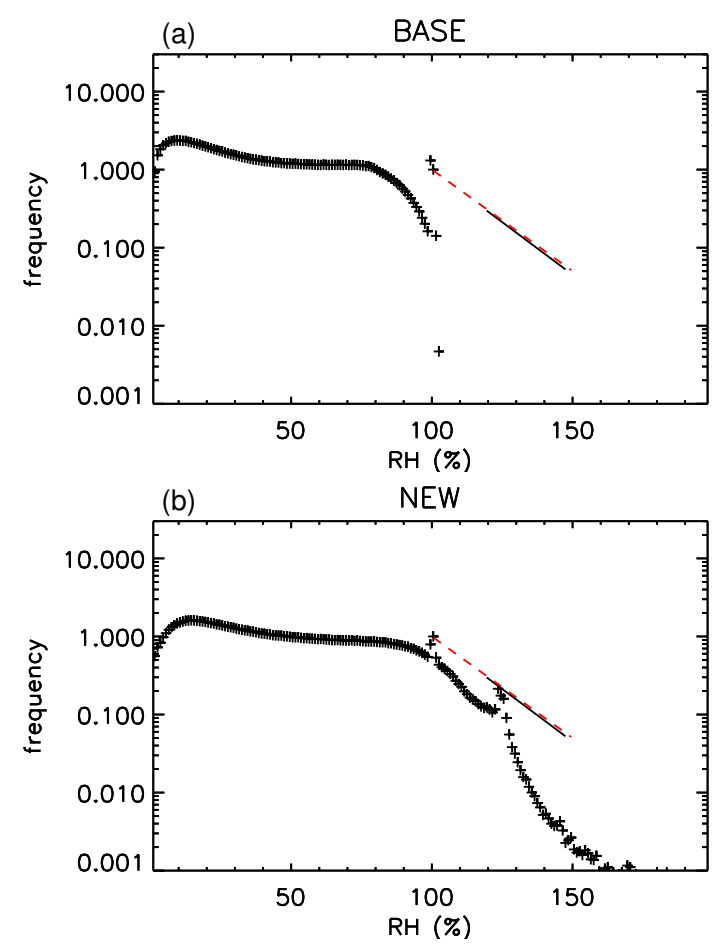

Fig. 5. Normalized (to $\mathrm{RH}=100 \%$ ) PDF of relative humidity with respect to ice outside clouds at the two model layers above and below $250 \mathrm{hPa}$ (crosses) and fits to climatological data from AIRS (red dashed line) (Gettelman et al., 2006) and to climatological data from MOZAIC observations (black solid line) (Gierens et al., 1999).

a given liquid water content, the Manton and Cotton (1977) parameterization ceases to be active beyond a certain droplet number concentration. Threshold-based approaches have, however, been criticized because the probability of collisions is always non-zero in disperse droplet distributions (Seifert and Beheng, 2001). The Khairoutdinov and Kogan (2000) parameterization, which is used in the NEW run, on the other hand, acts even at a low ratio of liquid water content to droplet number, which might help to explain the narrower PDF in the NEW run. A sensitivity run (not shown) confirms, that the variance of the droplet number decreases significantly if the Khairoutdinov and Kogan (2000) instead of the Manton and Cotton (1977) parameterization is used in the BASE run, but it remains larger than that in the NEW run.

Based on the fact that the stratiform LWP is similar in both schemes while the column integrated droplet number differs significantly, one might expect a pronounced difference in short-wave cloud forcing. However, since frequent occurrences of low numbers of super-cooled droplets are often associated with relatively low liquid water content, the discrepancy in the column integrated droplet numbers and in the PDF of $r_{\text {eff }}$ caused by super-cooled droplets has a smaller impact on short-wave radiation than one might anticipate solely based on Figs. 3a and 4.
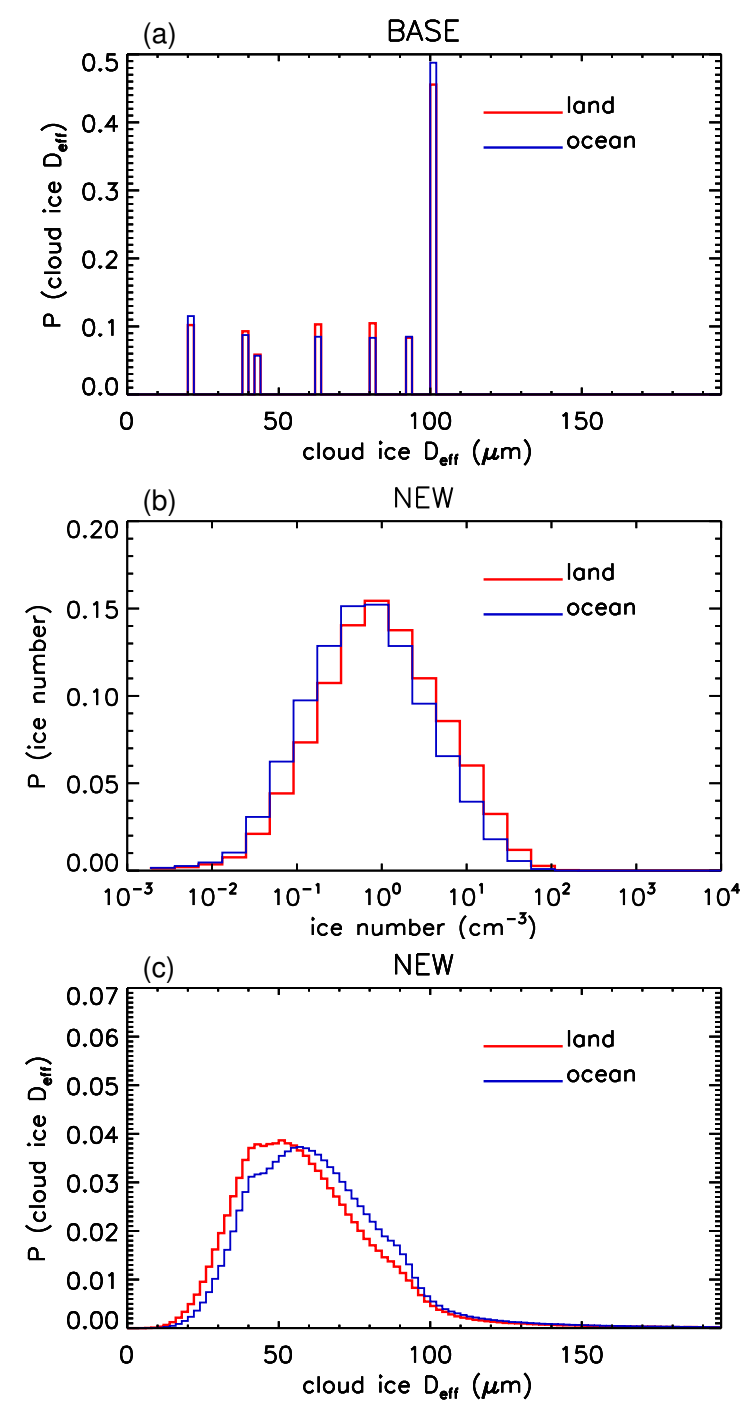

Fig. 6. (a) Global PDF of cloud ice effective diameter $\left(D_{\text {eff }}\right)$ from the BASE run. (b-c) In-cloud ice number concentration and cloud ice effective diameter $\left(D_{\text {eff }}\right)$ for the NEW run. Clouds with ice water content below $10^{-6} \mathrm{~kg} \mathrm{~m}^{-3}$ are excluded from this analysis.

\subsection{Super-saturation over ice}

High super-saturations over ice (occasionally exceeding $150 \%$ ) are observed in the upper troposphere and lower stratosphere and are a pre-requisite for homogeneous ice nucleation. While the original AM3 GCM stratiform cloud scheme does not allow grid-scale super-saturation over ice by explicitly limiting grid-box mean specific humidity to its saturation value, the new scheme permits super-saturation over ice in cloud-free air. The simulated PDF of relative humidity with respect to ice outside clouds $\left(\mathrm{RH}_{e}\right)$ agrees well with a fit to the climatological PDF of relative humidity in non-cloudy air from MOZAIC observations (for tropospheric air, fit range from 119 to $148 \%$, Gierens et al., 1999) for 

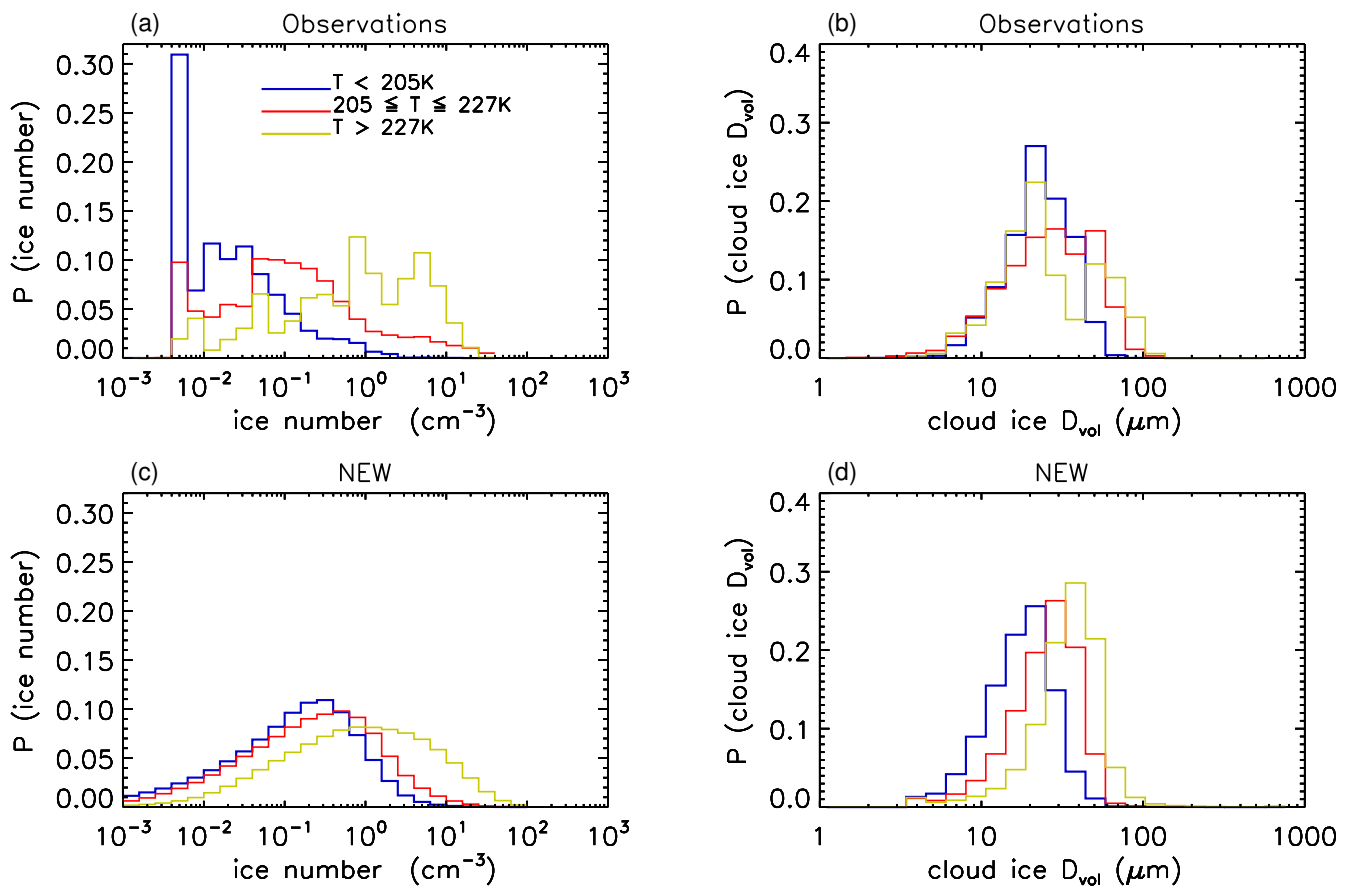

Fig. 7. Global PDF of cloud ice volume mean diameter $\left(D_{v i}\right)$ and in-cloud ice number concentration and for various temperature ranges compiled from aircraft observations (Krämer et al., 2009) and from the NEW run. Only ice clouds are considered, while mixed-phase clouds containing liquid have been excluded from this analysis.

$\mathrm{RH}_{e}<120 \%$ and also to a fit to AIRS data (Gettelman et al., 2006) for $250 \mathrm{hPa}$ and pixels with cloud cover below $70 \%$ (fit range from 100 to $150 \%$ ), which especially for this altitude range and normalization (to $\mathrm{RH}=100 \%$ ) is very similar to the MOZAIC data (Fig. 5). (Note that in cloud free grid boxes $\mathrm{RH}_{e}$ is equal to the grid-box mean $\left.\mathrm{RH}\right)$. For $\mathrm{RH}_{e}$ increasing beyond $120 \%$, high supersaturations over ice occur less frequently in the model compared to the MOZAIC and AIRS observations. If a higher minimum standard deviation of the $w$-PDF, $\sigma_{\min }$, is used in the ice nucleation parametrization, which is, however, not in line with the value observed for cirrus clouds by Kärcher and Ström (2003), the agreement at $\mathrm{RH}_{e}>120 \%$ improves (not shown).

\subsection{Cloud ice number and size PDFs}

The ice crystal size distribution in cirrus clouds has a significant effect on the Earth's radiation budget. For a given ice water content, smaller ice particles absorb infrared radiation more efficiently (e.g. Fu and Liou, 1993). In the BASE run, the effective diameter $D_{\text {eff }}$ of ice particles is determined from a temperature dependent lookup table (based on Donner et al., 1997) with a total of seven entries and there is no direct dependence of ice number concentrations on aerosols. This is reflected in the PDF in Fig. 6a. In the NEW run, on the other hand, ice nucleation depends among others on sulfate and dust concentrations. The PDFs of ice number concen- tration and effective radius from the NEW run are shown in Figs. $6 \mathrm{~b}$ and c. There is a significant land-ocean contrast, indicating some susceptibility of these quantities to changes in aerosol concentrations under typical present day atmospheric conditions. This should, however, not be over-interpreted. While global mean PDFs can for example help to identify general differences between different microphysics schemes, they do not reflect radiative impacts well, for which certain regions such as the tropical upper troposphere can play a disproportionately important role.

Simulated in-cloud ice number concentrations and effective radii for three different temperature intervals are compared to observations in Fig. 7. Here, only ice clouds are considered while mixed-phase clouds containing liquid have been excluded from the analysis of the model results. Krämer et al. (2009) analyzed number concentrations of ice crystals from FSSP (Forward Scattering Spectrometer Probe) measurements which were recorded during 20 flights in the framework of seven field campaigns in the Arctic, at midlatitudes, and in the tropics. Volume mean diameters are derived from observed number concentrations and IWC detected by the FISH (Fast in-situ Stratospheric Hygrometer) closed Lyman- $\alpha$ fluorescence hygrometer. The temperature dependence of the simulated ice number PDFs in Fig. 7 qualitatively agrees with observations, although some differences exist, especially at low temperatures. While the reason for the peak in observed $N_{i}{ }^{\prime}$ at low temperatures in Fig. 7 is still 

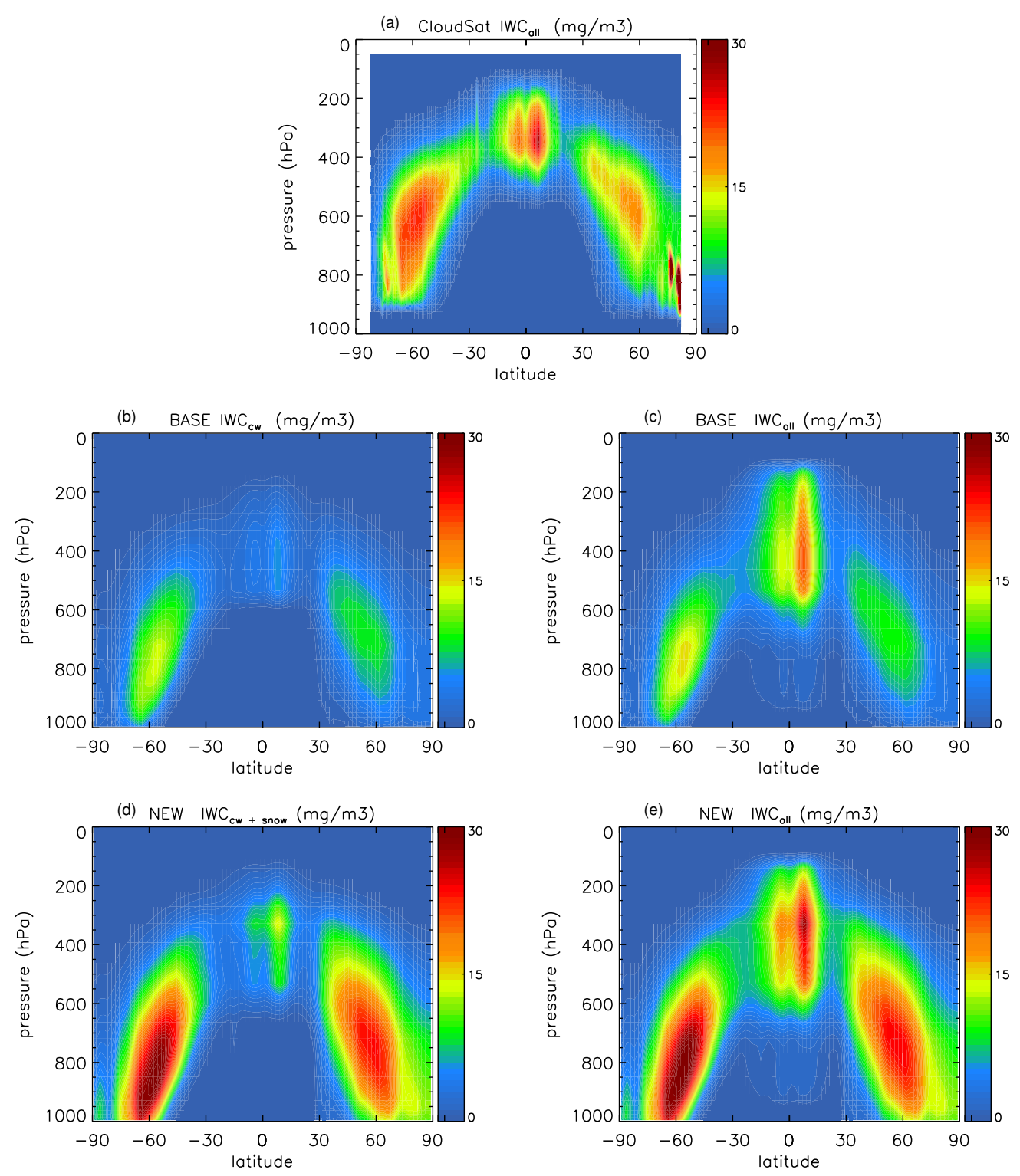

Fig. 8. Grid-box zonal mean ice water content (IWC) compared to "all sky" CloudSat retrievals (Waliser et al., 2009). Below 850 hPa CloudSat (a) has sampling problems and hence there is no low-level IWC shown in (a). Stratiform IWC is shown in (b) for the BASE run and in (d) for the NEW run, for which the stratiform IWC includes diagnosed snow. The total IWC shown in (c) for the BASE run and in (e) for the NEW run also contains contributions from deep convective anvils and updrafts and from shallow convection.

being investigated, the simulated PDF for $T<205 \mathrm{~K}$ is clearly skewed towards higher ice number concentrations compared to the observations. Furthermore, the difference between the PDFs for $T<205 \mathrm{~K}$ and $205 \leq T \leq 227 \mathrm{~K}$ is smaller in the model than in the observations. The reason for this discrepancy is at present unclear. For $T>227 \mathrm{~K}$ (where Meyers' empirical formula is applied), the observed and the simulated ice number PDFs agree well. The uncertainty associated with the simulated and the observed ice numbers for $T>227 \mathrm{~K}$ is, however, substantial. In particular, it can not be excluded that ice crystal shattering on the inlet (Heymsfield, 2007; McFarquhar et al., 2007) of the FSSP contributes to the observed ice numbers at the warmer temperatures (Krämer et al., 2009), so that the good agreement for $T>227 \mathrm{~K}$ in the present study could be coincidental.

The PDFs of simulated cloud ice volume mean diameter are generally narrower than observed, but there is significant overlap between the observations and the model.

\subsection{Cloud ice water content}

There are still only very few satellite retrievals of ice water content available. So-called "satellite simulators", i.e. model components which are used to simulate radiances as 

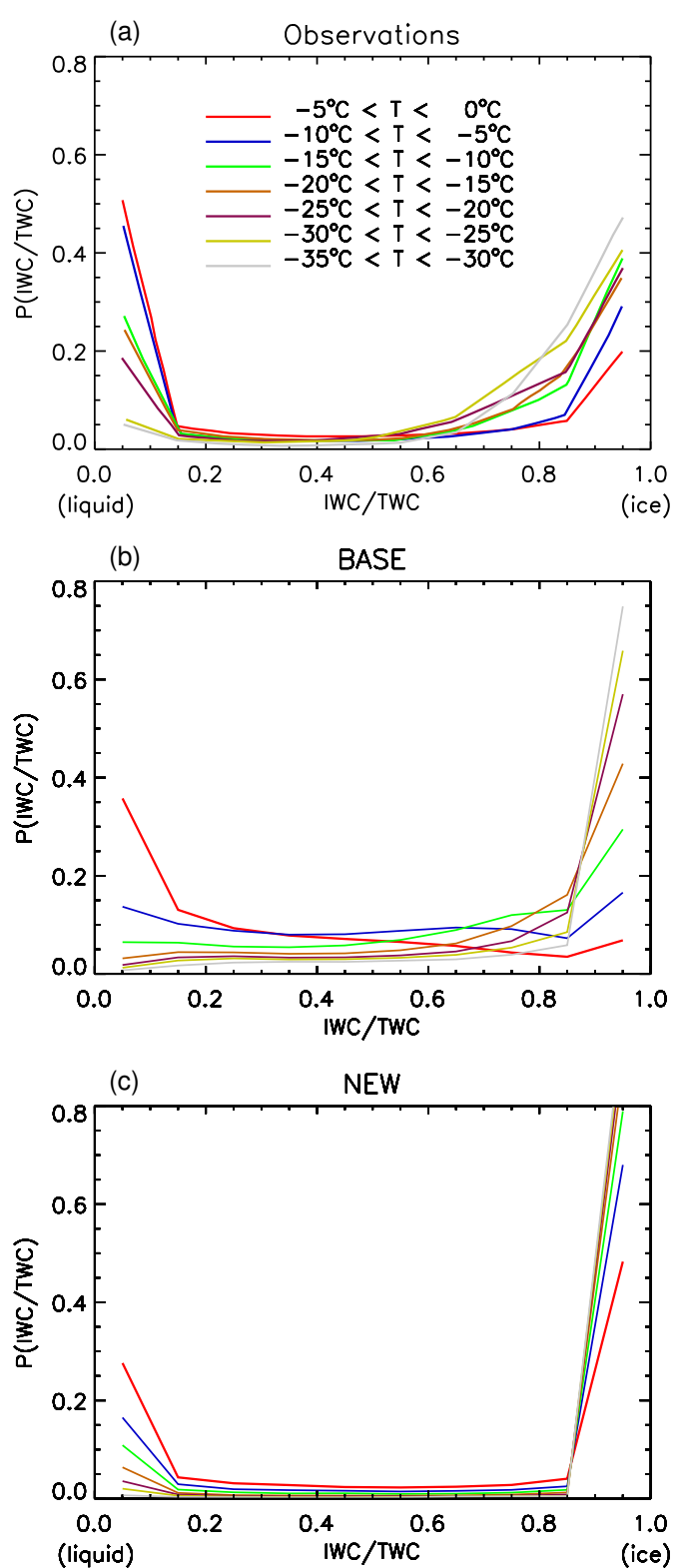

Fig. 9. PDFs of mixed-phase cloud glaciated fraction (IWC/TWC), where total stratiform water content $\mathrm{TWC}=\mathrm{LWC}+\mathrm{IWC}$, for different temperature intervals compared to observations from Korolev et al. (2003). For the NEW scheme, TWC includes diagnosed rain and snow. Observations are representative of a horizontal scale on the order of $100 \mathrm{~m}$.

observed by satellites based on model simulated hydrometeor distributions, are increasingly becoming available, and will help to evaluate modeled ice hydrometeor properties. At present, a number of these simulators are still undergoing significant development and have not yet been available for the purpose of this study. Instead, we evaluate simulated zonal mean ice water content using a recent dataset based on CloudSat observations (Waliser et al., 2009). Figure 8 shows model simulated grid box mean IWC in comparison to CloudSat data. As in Sect. 3.1, the analysis of the strati- form IWC in the BASE run is limited to the prognostic cloud ice variable, while a diagnostic snow variable is included in the analysis of the NEW run. If a diagnostic snow concentration were also included in the analysis of the BASE run, the total zonal mean IWC in the this run would be closer to the CloudSat IWC. By far the largest contribution to ice in the tropical upper troposphere is from anvils in the deep convection parameterization, which are simulated to cover a small area and therefore (unlike detrainment) have a limited effect on radiation. The anvils are assumed to consist exclusively of ice, even in the cases in which the lowest level contained in the anvil is located above $0{ }^{\circ} \mathrm{C}$. Figure $8 \mathrm{c}$ and e suggest that some anvils extend down to about $600 \mathrm{hPa}$, which is not far from the climatological $0{ }^{\circ} \mathrm{C}$ level in the tropics. While this is not anticipated to have a large impact on radiation, it is a subject for a future improvement. On the whole, the zonal mean structure of the simulated IWC and those derived from satellite observations show a number of similarities, although significant uncertainties still exist in the model as well as in the satellite retrievals.

\subsection{Mixed-phase clouds}

The simulation of mixed-phase clouds is evaluated based on observations by Korolev et al. (2003). Korolev et al. (2003) measured cloud liquid water content (LWC) and total water content (TWC) using different sensors of a Nevzorov probe during several aircraft campaigns at mid- and high latitudes. Figure 9a shows PDFs of the cloud glaciated fraction as expressed by the ratio $\gamma=\mathrm{IWC} / \mathrm{TWC}$ for seven temperature intervals between 0 and $-35^{\circ} \mathrm{C}$. Clouds are considered liquid if $\gamma$ is less than $10 \%$ and ice, if $\gamma$ exceeds $90 \%$ (Korolev et al., 2003). For any individual measurement (corresponding to a horizontal scale on the order of $100 \mathrm{~m}$ ), clouds tended to be either liquid or glaciated due to the WBF process. The higher occurence of $\gamma$ between 0.6 and 0.9 could be related to a measurement problem (Lohmann et al., 2007, based on A. Korolev, personal communication, 2006). The BASE run (Fig. 9b), on the other hand, contains a large fraction of grid boxes with $0.1<\gamma<0.9$, which is not present in the observations by Korolev et al. (2003). Although Korolev's observations suggest that clouds tend to be composed of either liquid or ice on the scale of order $100 \mathrm{~m}$, this is almost certainly not true at the scale of a GCM grid-box. Therefore, these observations are not directly comparable to grid-box averages from a GCM, and one could argue that the large fraction of boxes containing both liquid and ice in the BASE run represents either spatial inhomogeneity within clouds or grid boxes frequently containing liquid as well as ice clouds at a given level. However, neither is spatial inhomogeneity inside clouds explicitly taken into account in the model formulation, nor is a distinction made between separate liquid and ice clouds in the same grid box. Instead, in the implementation of the WBF process it is assumed that ice and liquid are evenly mixed within the cloudy part of the grid box in 

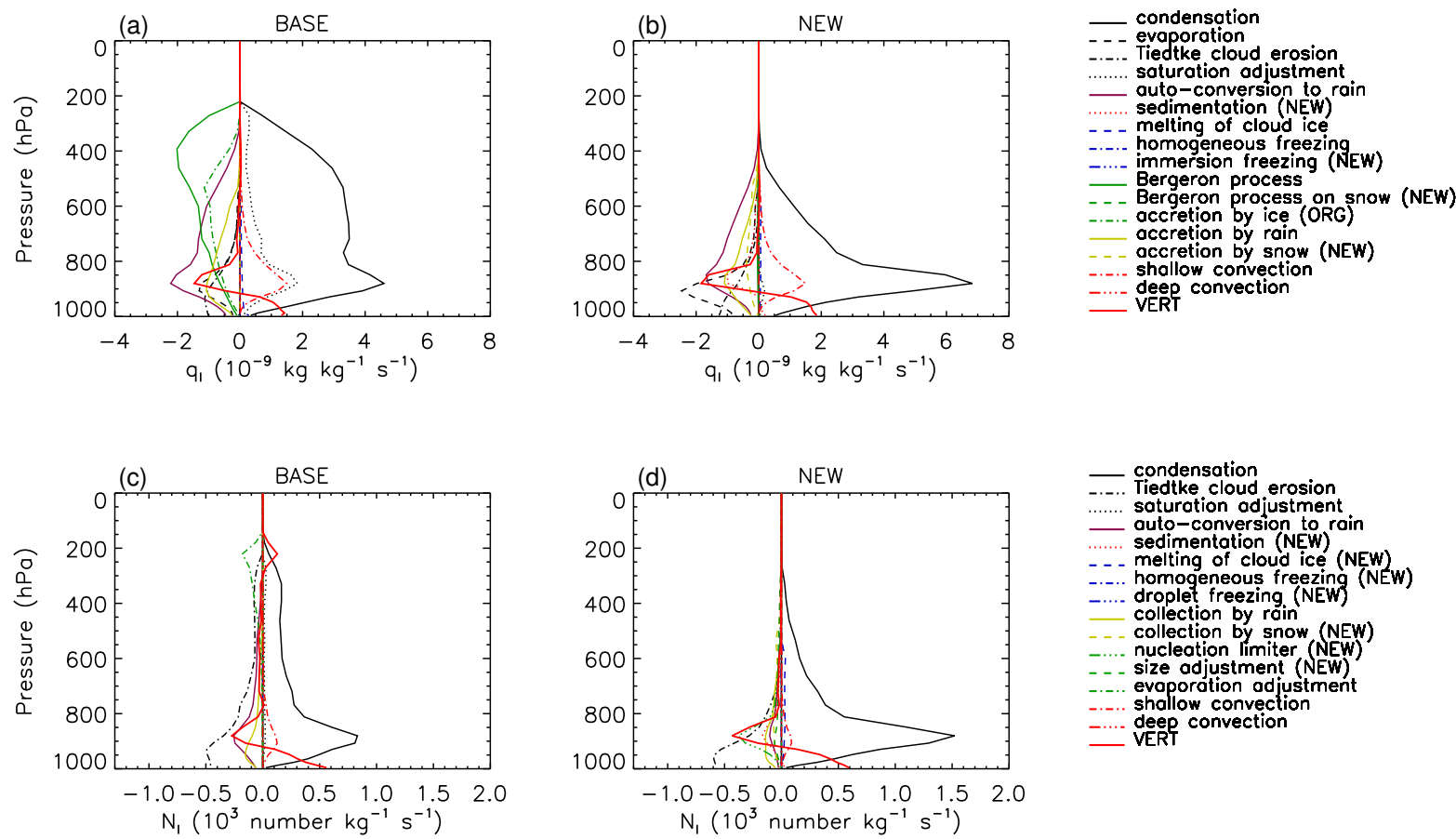

Fig. 10. Global budgets of cloud (droplet) liquid water amount (a and b), liquid droplet number (c and d). Legends are provided for each row. If a term is only calculated in one of the runs, the name of the run is indicated in brackets. VERT stands for vertical advection and turbulence.
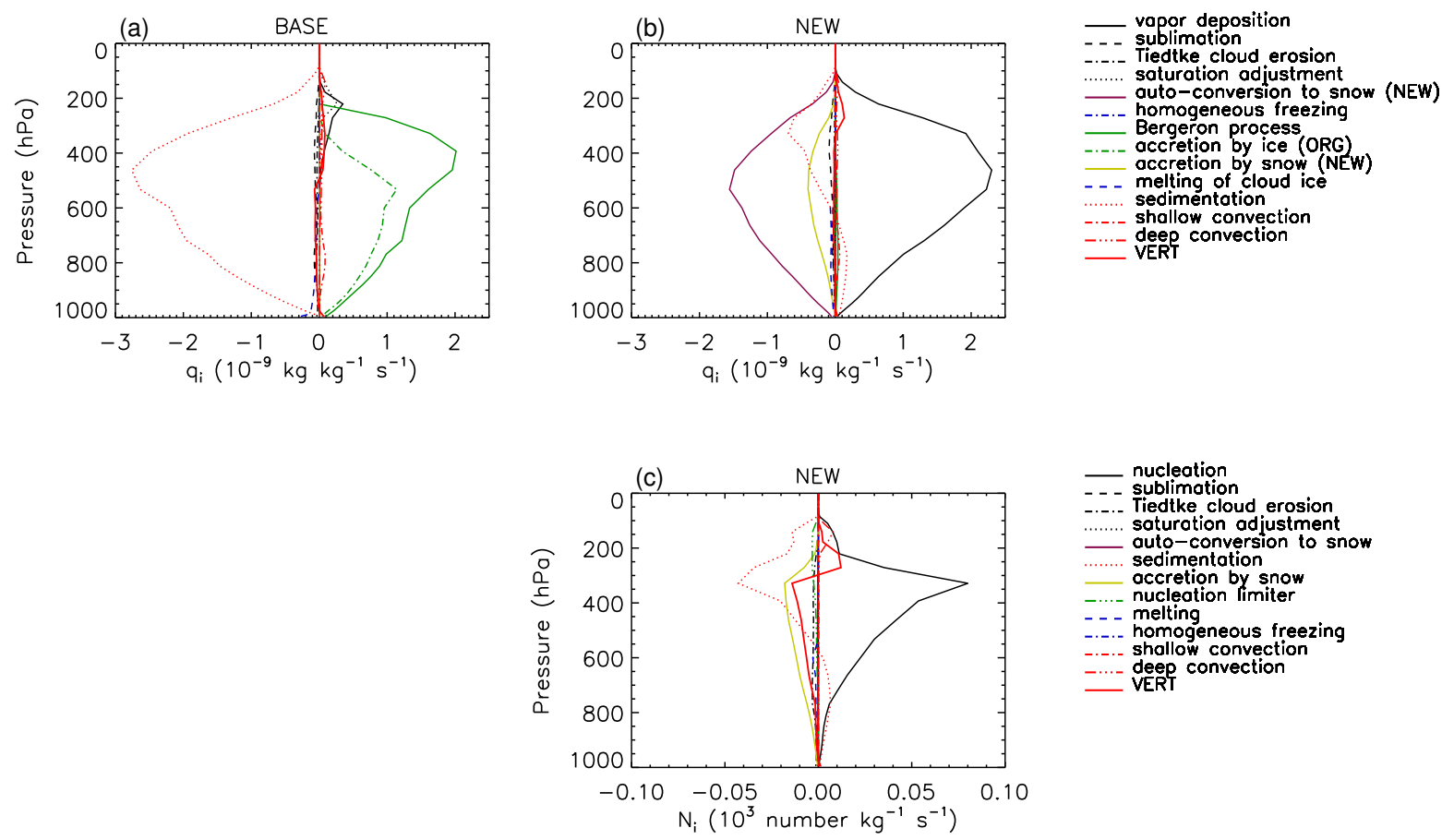

Fig. 11. As Fig. 10 but for ice water amount (a and b), and for cloud ice particle number in the NEW run (c). 
both schemes, which is expected to lead to a stronger WBF process than if the liquid and ice were contained in separate parts. Rotstayn et al. (2000) considered results obtained using the uniformly mixed assumption more realistic than those obtained using the horizontally adjacent assumption, but neither of these two extreme assumption is likely to be realistic on the scale of a GCM grid box. The reason for the significant fraction of partially glaciated clouds in the BASE run in spite of the assumption that liquid and ice is uniformly mixed is discussed in Sect. 4.1.

In the NEW run (Fig. 9c) clouds are usually either liquid or completely glaciated, which is in-line with the well mixed assumption. The fairly small fraction of partially glaciated clouds (which would become even smaller if rain and snow were not taken into account in the analysis) indicates that once ice is present, the WBF process is very efficient at removing liquid water. This is also reflected by the smaller number of super-cooled droplets in the NEW run as indicated in Sect. 3.1 (Fig. 3a). If the IN concentration is determined using Meyers' formula as applied in the BASE run, the fraction of partially glaciated clouds in the NEW run decreases slightly (not shown). Korolev (2007) has pointed out that the WBF process (growth of ice crystals at the expense of liquid droplets) is expected to occur only under the condition that $e_{s}>e>e_{i}$, where $e$ is the actual vapor pressure and $e_{s}$ and $e_{i}$ are the saturation vapor pressures with respect to liquid water and ice. Conversely, if $e>e_{s}$, liquid water and ice are expected to compete for the available excess water vapor. Since the adjustment time to liquid saturation is usually smaller than the typical timestep in a GCM, the WBF process is currently allowed to influence the phase partitioning even if $e>e_{s}$ at the beginning of the microphysics calculations. Furthermore, vapor pressures in a GCM are grid-box averages, while the limits proposed by Korolev (2007) apply to localized vapor pressures, which vary. Results from a short sensitivity run (not shown) indicate that limiting the WBF process to cases in which $e<e_{s}$ would not increase the fraction of partially glaciated clouds significantly in the NEW run. In order to arrive at a better description of mixed-phase clouds in GCMs at the present relatively coarse horizontal resolution, one could try to devise a cloud scheme that facilitates more realistic assumptions on the spatial relationship of ice and liquid water within grid boxes. As horizontal resolutions increases, this issue (among others) is, however, expected to eventually become less significant.

\subsection{Budgets}

Budgets of $q_{l}, N_{l}, q_{i}$, and $N_{i}$ are depicted in Figs. 10 and 11. Contributions from individual processes have been calculated by horizontally integrating the tendency terms in the corresponding prognostic equations, except for the vertical advection and turbulence (VERT) term, which is obtained as a residual. In order to validate the budget diagnostics, it has been ensured that the sum of all individual contributions ex- cept for the VERT term agrees well with a combined budget term which has been diagnosed independently.

A comparison of Fig. 10a and $b$ yields several major differences in the $q_{l}$ budget. Most notably, in the BASE run condensation acts as a significant source of cloud water throughout the upper troposphere, where it is largely balanced by the WBF process. As will be shown in Sect. 4.1, the underlying difference in the treatment of the WBF process is also largely responsible for the higher concentrations of supercooled droplets in the BASE run previously shown in Figs. 3a and 4 . The saturation adjustment term plays a large role in the BASE run, but not in the NEW run due to the limitations on $q_{v}^{\max }$ and on evaporation described in Sect. 2.2.2, which can be viewed as another form of saturation adjustment. In the original implementation of the Tiedtke scheme, the condensation term fails to remove grid scale supersaturation in subsidence regions and the E1 evaporation term acts even under conditions of grid-scale supersaturation. Supersaturation is removed by the saturation adjustment term which is the second most important source term of liquid condensate in the BASE run. In the BASE run it is assumed that the saturation adjustment term contributes to the formation of cloud water rather than being instantaneously removed by precipitation as in Tiedtke (1993). The Tiedtke E1 evaporation term is calculated prior to microphysics while the saturation adjustment is performed after the microphysics calculations in the original implementation. This can result in the microphysics scheme not "seeing" a part of the condensate which should be present based on saturation adjustment arguments. In the lower troposphere, "cloud erosion" constitutes a significant sink of cloud water in the BASE and the NEW run. The "erosion coefficients" are not well constrained by observations, but unlike E1 evaporation in the original Tiedtke (1993) scheme, "cloud erosion" can only take place if the grid-box mean humidity is below saturation. Figure 10a and $\mathrm{b}$ also illustrate the interplay of the cloud cover and the microphysics scheme as suggested by the global balance of terms. This indicates the need for studies which focus on studying these parameterizations in combination with each other in addition to studies in which they are assessed in isolation from each other.

The droplet number budgets in Fig. 10c and d reflect some of the differences discussed in relation to Fig. 10a and b. Furthermore, there are several differences regarding the role of individual processes. The size adjustment term (Morrison and Gettelman, 2008), which prevents unrealistic mean particle size and can either be a local source or sink term, is a small net sink for droplet number. The nucleation limiter prevents the number of droplets $N_{l}$ from exceeding the maximum number of activated droplets $N_{l, \text { act }}^{*}$ by limiting $N_{l}$ to $N_{l, \text { act }}^{*}$. Decreasing the importance of the nucleation limiter would presumably require a more consistent treatment of aerosol scavenging. 


\section{(a)}

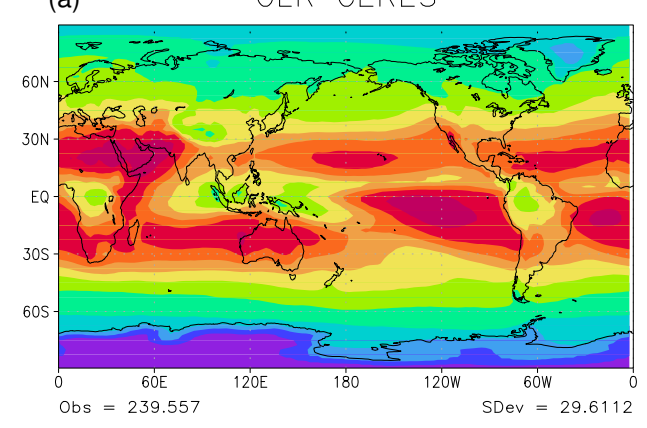

(c) OLR: BASE minus CERES

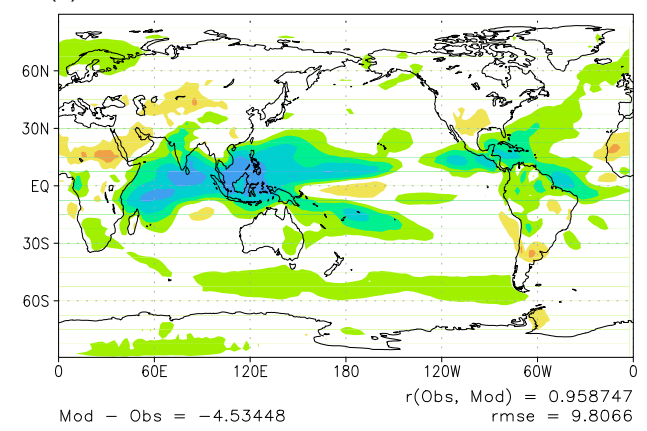

(e) OLR: NEW minus CERES

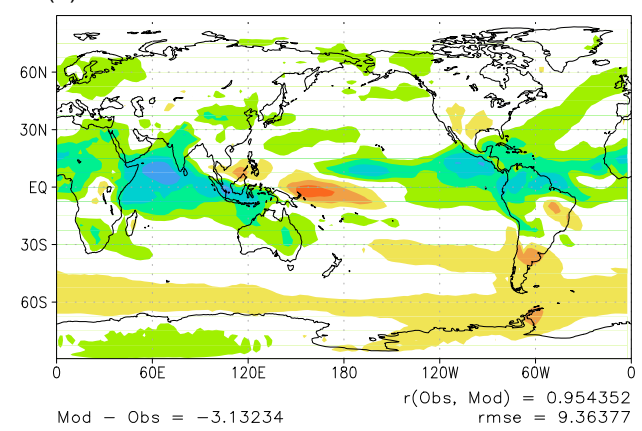

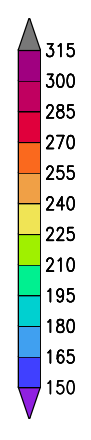
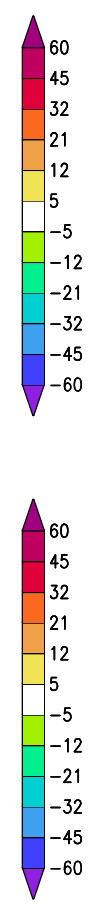

(b)
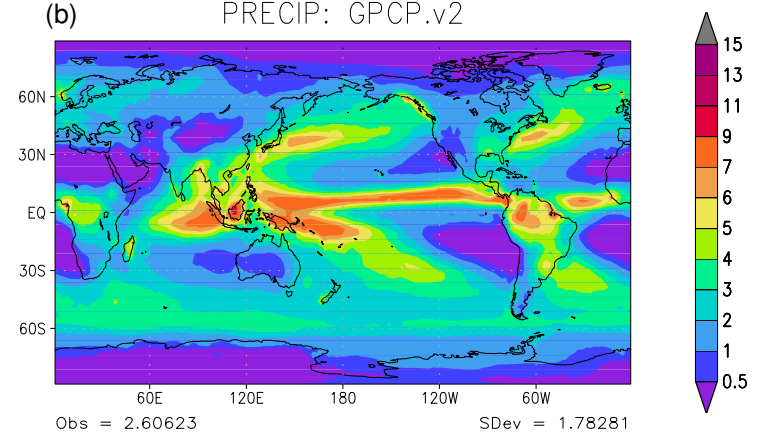

(d) PRECIP: BASE minus GPCP.v2
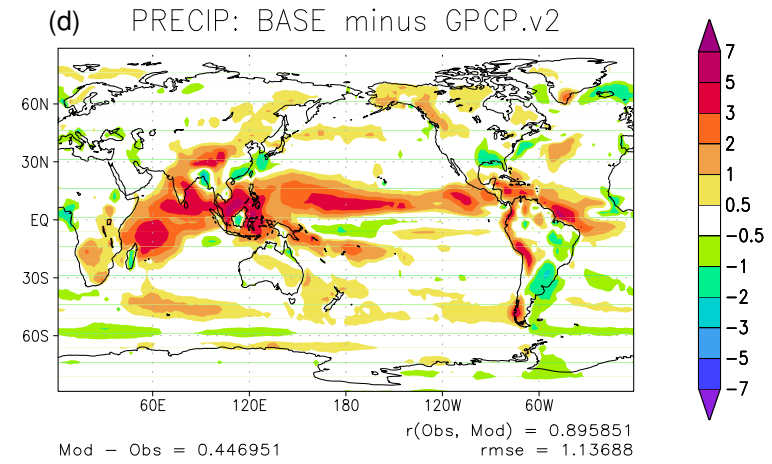

(f) PRECIP: NEW minus GPCP.v2

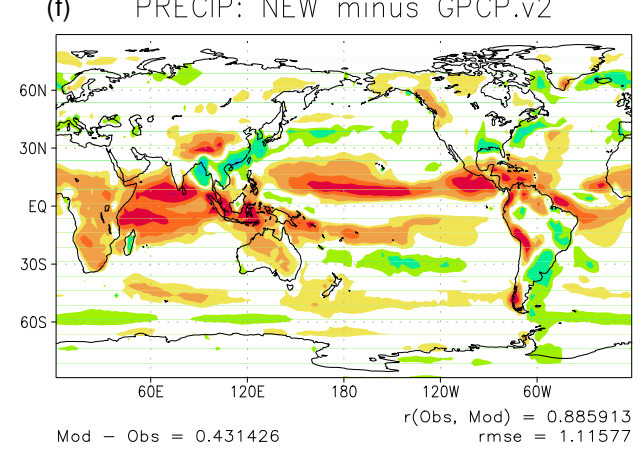

Fig. 12. (a) Outgoing long-wave radiation for March 2000 through February 2005 form the CERES-EBAF dataset (Loeb et al., 2009), (c) difference BASE - CERES-EBAF, (e) NEW - CERES-EBAF, (b) GPCPv2 observation based estimate of surface precipitation, (d) difference BASE - GPCPv2, (f) NEW - GPCPv2. Horizontal averages are indicated in the lower left corner of each panel. SDev is the standard deviation, $\mathrm{r}$ (obs,mod) is the correlation coefficient, and rmse the root mean square error (in the lower right corner of each panel).

The main source terms in the $q_{i}$ budget (Fig. 11a and b) again reflect differences in the treatment of the WBF process, which in the NEW run is already included in the vapor deposition tendency. The main sink term in the BASE scheme is sedimentation, while in the NEW run auto-conversion to snow and accretion by snow dominate in the lower troposphere. (Recall that snow is not represented as a separate variable in the BASE scheme.) Vertical advection and detrainment from deep and shallow convection constitute a small contribution to the $q_{i}$ budget. In the $N_{i}$ budget (Fig. 11c), which is only calculated for the NEW run, vertical advection and also deep convection play more significant roles. In particular, upward transport by the grid-box aver- age vertical velocity leads to a net increase of ice number concentrations at $\sim 200-300 \mathrm{hPa}$, where the nucleation term has a minimum. At its maximum the contribution of vertical advection to the ice number budget is almost equal to the contribution from nucleation. This suggest that vertical advection of ice number due to the grid-box average vertical velocity could potentially play a role for upper tropospheric ice numbers, although the importance of this process in the simulations certainly depends on the nucleation formulation. Vertical advection of ice number is not represented explicitly in the BASE run, since $N_{i}$ is not a prognostic variable. 


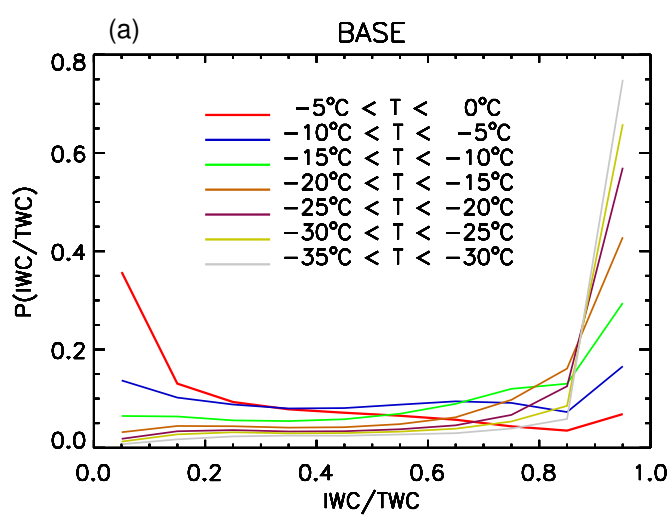

(b)

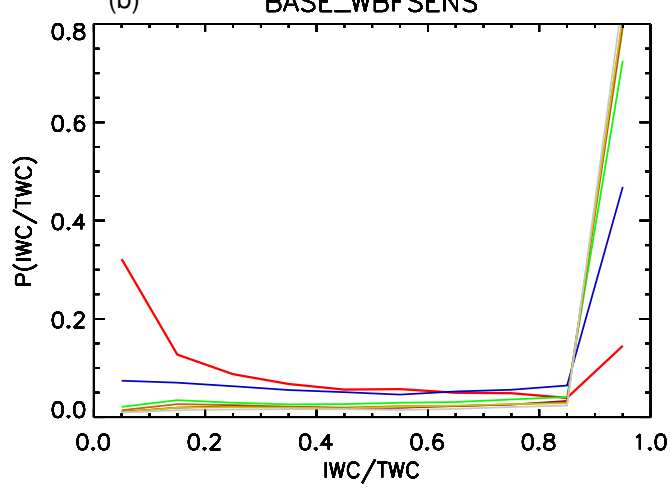

Fig. 13. As Fig. 9 for the BASE and the WBFSENS sensitivity run.

\subsection{Outgoing long-wave radiation and cloud radiative forcing}

In Fig. 12a,c, and e simulated OLR is compared to the CERES-EBAF (EBAF: Energy Balanced and Filled) dataset from Loeb et al. (2009). In generating the CERES-EBAF dataset, radiative fluxes have been adjusted in order to decrease the net radiation flux at the top of the atmosphere so that it becomes compatible with the estimate of heat storage in the earth-atmosphere system by Hansen et al. (2005). The global average OLR in the NEW run is within the range of estimates (235.8-240.4 $\mathrm{W} \mathrm{m}^{-2}$ ) from various satellite observations compiled by Loeb et al. (2009), but is below the CERES-EBAF average (see Loeb et al. (2009) for a detailed discussion on the uncertainties). In the BASE run, it is slightly lower than the lower bound of the estimates compiled by Loeb et al. (2009). The largest model bias is found in maritime tropical regions, especially in the south Asian monsoon region and the western Pacific. These regions are strongly influenced by deep convection, and biases in simulated precipitation with respect to GPCVv2 precipitation estimates (Fig. 12d and f) are significant there as well. While a part of this bias might be explained by interactions between the deep convection and the microphysics parameterization, the main reason is probably related to uncertainties in sim- ulating the intensity (cloud top height) and location of deep convection, which depends for example on the closure assumptions in the deep convection parameterization. In addition, a positive OLR bias in the southern oceans exists in the NEW run, where biases in SWCF and LWCF in Fig. 3 are also large. These biases are most likely related to the representation of aerosol-ice interactions. In particular, there is little aerosol other than sea-salt simulated to exist in this region, as indicated by the dominance of the contribution of sea salt to the total AOD in Fig. 2a. Not scaling Meyers' formula by dust concentration (see Eq. 17) reduces the bias in the southern ocean, but also increases the tropical OLR bias (not shown). An alternative is to scale Meyers' formula by a climatological vertical profile of dust concentrations as in Liu et al. (2007), but this does take into account the large difference between average Northern and Southern hemispheric dust concentrations (e.g. Minikin et al., 2003). Taking into account homogeneous freezing of deliquescent sea salt aerosols in analogy to sulfate (mainly affecting the very cold upper troposphere) does not reduce the southern ocean bias significantly (not shown). Increasing the fraction of ice detrained from deep convection in the NEW run from $3 \%$ to $5 \%$ (corresponding to the value in the BASE run) yields a sligtly lower correlation ( $r=0.94$ vs. 0.95 ), higher root mean square error (rmse=11.2 vs. 9.4), and larger bias $\left(-4.5 \mathrm{~W} \mathrm{~m}^{-2}\right.$ vs. $\left.-3.1 \mathrm{~W} \mathrm{~m}^{-2}\right)$ and a similar difference pattern as Fig. 12b. Further research on the couplings of deep convection and stratiform cloud microphysics is warranted.

\section{Sensitivity studies}

\subsection{Implementation of the WBF process}

In the preceding sections, we have attributed major differences in column integrated droplet number (Fig. 3a) and in the global PDF of drop size distribution (Fig. 4) to a difference in the liquid/ice phase partitioning (Fig. 9). Here we present results from a one-year sensitivity run which suggests that these differences can at least in part be explained the differences in the implementation of the WBF process discussed in Sect. 4.1. The WBFSENS sensitivity run is based on the BASE run, but instead of assuming all newly formed condensate initially to be liquid down to $-40^{\circ} \mathrm{C}$ in the integration of the $q_{l}$ equation, the condensation/deposition rate (which in the BASE run contributes only to liquid water above $-40{ }^{\circ} \mathrm{C}$ ) is partitioned into a condensation $\left(\partial q_{l} /\left.\partial t\right|_{\text {strat }}\right)$ and a nonzero deposition rate $\left(\partial q_{i} /\left.\partial t\right|_{\text {strat }}\right)$ depending on a preliminary estimate of the ice deposition rate prior to performing the microphysics calculations. Figure $13 \mathrm{~b}$ shows that this reduces the fraction of partially glaciated clouds, especially between $-10^{\circ} \mathrm{C}$ and $-20^{\circ} \mathrm{C}$. Changing the initial partitioning of the condensation/deposition rate also significantly reduces the contribution of super-cooled droplets to the column integrated droplet number (Fig. 14) as expected based 
on Fig. 13. While the procedure used in the WBFSENS sensitivity run is similar to the one used in the NEW scheme, it is not fully consistent with the original design of the BASE scheme. One could nevertheless argue that this highly simplified sensitivity experiment adds to the experience that numerics can play an important role. As far as possible, these details should be considered in evaluating models, and efforts aimed at addressing uncertainties related to numerics in microphysics schemes should be sustained in the future. Although it is difficult to determine which method for treating the WBF process is more correct, one could argue that the results obtained with the MG08 scheme are more in line with the results one would expect based on the assumption of ice and liquid being homogeneously mixed inside the grid box instead of being spatially separated, which is common to both schemes. Further research on this issue is warranted.

\subsection{Anthropogenic aerosols}

In order to assess the sensitivity of cloud properties to changes in aerosol concentration, we have performed several 5-year integrations with pre-industrial aerosols (PIA), but present-day sea-surface temperatures (SSTs) and compared them to simulations for present-day aerosols (PDA). The resulting change in net radiation at the top of the atmosphere corresponds to the aerosol radiative flux perturbation (RFP) as defined in Haywood et al. (2009); Lohmann et al. (2010) and differs from the IPCC definition of radiative forcings (Haywood et al., 2009; Lohmann et al., 2010). It includes fast atmospheric responses to changing aerosols (both direct radiative and cloud related semi- and indirect effects), while suppressing slower responses due to global seasurface temperature change. In addition to changing aerosol and aerosol precursor (in particular sulfur dioxide) emissions to estimates for the year 1860 (from Lamarque et al., 2009) in the PIA simulations, we also specify concentrations of trace gases (in particular hydrogen peroxide and other oxidants) based on results from an AM3 simulation for the year 1860 in which photochemistry has been included. Differences (PDAPIA) between 5-year integrations with identical SSTs (years 2000-2004) for the BASE and the NEW model are summarized in Table 3. Global mean AOD decreases by roughly one third in the PIA runs compared to the PDA runs, in accordance with lower anthropogenic emissions. The difference in global mean precipitation is very small as expected in a setup with fixed SSTs, and does not represent an estimate of the actual change in precipitation due to the impact of anthropogenic activity. The liquid water path increases by $2 \%$ in the BASE PDA run and by as much as $5 \%$ in the NEW PDA run (rain included, compare Table 2). Changes in IWP are much smaller. Total cloud cover (TCC) increases slightly in both runs which can be associated with an increase in cloud lifetime and/or of an increase in horizontal extent.

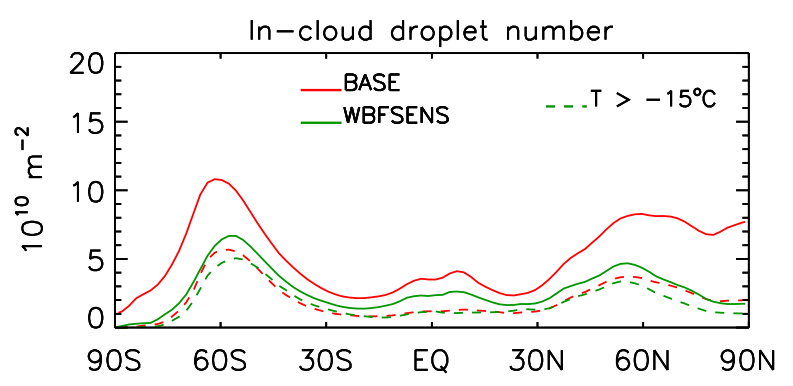

Fig. 14. As Fig. 3a for the BASE and the WBFSENS sensitivity run.

The short-wave cloud forcing (SWCF) becomes more negative in both PDA simulations which is in line with clouds being more reflective. LWCF increases in the NEW PDA run, and decreases slightly in the BASE PDA run. Short-wave absorption (SWABS) decreases in both runs, but the decrease is more pronounced in the NEW run. The global mean OLR decreases more strongly in the NEW run than in the BASE run, and the OLR decrease in the NEW run is stronger than the increase in LWCF indicating that cloud cover changes play a role. Sensitivity runs based on the NEW run in which the maximum ice particle number $N_{i \text {,nuc }}^{*}$ is diagnosed based on temperature only (similar to MG08, not shown) and in which the Liu et al. (2007) ice nucleation parameterization is turned off, yield a similar decrease in OLR for PDA vs. PIA setups. Consequently, this decrease in OLR can not be attributed to the effect of anthropogenic sulfate on cirrus clouds. While additional sensitivity runs would be necessary in order to elucidate the underlying mechanisms, it should be noted that the main objective of this section is to demonstrate that the new scheme is capable of producing a reasonable aerosol RFP. The aerosol RFP $=\Delta$ SWABS- $\Delta$ OLR (i.e. the PDA-PIA difference in net radiation at the top of the atmosphere, where netradTOA $=$ SWABS-OLR) is slightly larger in the NEW run than in the BASE run, but still smaller than the expected increases related to increasing greenhouse gas concentrations. In the NEW run it is also smaller than expected from the change in SWABS alone. Considering black carbon instead of dust as immersion IN in the cirrus cloud regime could potentially lead to an increase in aerosol RFP, but the efficiency of soot as immersion IN is not well established. Since there is considerable inter-annual variability in netradTOA, it is likely that longer integrations and/or ensembles would yield slightly different values of aerosol RFP. A set of sensitivity runs based on the NEW run in which $\sigma_{\text {min }}$ and $f_{\text {adi }}$ were reset to their original values without re-tuning for radiation balance, on the other hand, yields similar results as in Table 3, indicating that the results of this section do not critically depend on these choices. 
Table 3. Differences present-day minus pre-industrial aerosols ${ }^{1}$.

\begin{tabular}{lrr}
\hline Simulation & BASE & NEW \\
\hline$\Delta$ AOD & 0.047 & 0.045 \\
$\Delta \mathrm{P}_{\text {tot }}\left(\mathrm{mm} \mathrm{d}^{-2}\right)$ & -0.013 & -0.023 \\
$\Delta \mathrm{LWP}_{\text {tot }}\left(\mathrm{g} \mathrm{m}^{-2}\right)$ & 1.26 & 3.11 \\
$\Delta \mathrm{IWP}$ tot $\left(\mathrm{g} \mathrm{m}^{-2}\right)$ & -0.42 & 0.47 \\
$\Delta \mathrm{TCC}(\%)$ & 0.15 & 0.15 \\
$\Delta \mathrm{SWCF}\left(\mathrm{W} \mathrm{m}^{-2}\right)$ & -0.57 & -0.98 \\
$\Delta \mathrm{LWCF}\left(\mathrm{W} \mathrm{m}^{-2}\right)$ & -0.05 & 0.19 \\
$\Delta \mathrm{SWABS}\left(\mathrm{W} \mathrm{m}^{-2}\right)$ & -1.71 & -1.99 \\
$\Delta$ OLR $\left(\mathrm{W} \mathrm{m}^{-2}\right)$ & -0.12 & -0.31 \\
$\Delta$ netradTOA $\left(\mathrm{W} \mathrm{m}^{-2}\right)$ & -1.59 & -1.68 \\
\hline
\end{tabular}

${ }^{1} 5$-year integrations with fixed SSTs.

\section{Summary and discussion}

A new stratiform cloud scheme including a modified version of the Tompkins et al. (2007) cloud cover parameterization has been implemented into the GFDL AM3 GCM and various aspects of the modified model have been evaluated based on satellite and in-situ observations. The stratiform cloud liquid and ice water path is similar in the BASE and the NEW run, but the column integrated droplet number and the global frequency distribution of simulated droplet effective radii differ significantly. The global mean total ice water path in the NEW run $\left(108 \mathrm{~g} \mathrm{~m}^{-2}\right)$, which includes contributions from convective clouds and snow, is at the upper end of the range of uncertainty derived from CloudSat observations (Austin et al., 2009; Waliser et al., 2009), in part due to an over-estimate in the tropics, where stratiform clouds and deep convective anvils contribute significantly to the total.

An idealized sensitivity run suggests that significant differences in the column integrated cloud droplet numbers and the global PDF of simulated droplet effective radii between the BASE and the NEW run can in large part be explained by a difference in the implementation of the Wegener-BergeronFindeisen process. On the whole, clouds in the NEW run tend to be more likely to be either glaciated or liquid due to the WBF process, which is in qualitative agreement with observations by Korolev et al. (2003). Simulated supersaturations over ice in the NEW run are in qualitative agreement with observations and global frequency distributions of ice numbers and effective radii appear reasonable in the light of observations. The temperature dependence of ice numbers qualitatively agrees with aircraft observations from several campaigns recently compiled by Krämer et al. (2009), but the description of ice nucleation is still subject to major uncertainties, and a more rigorous treatment would be desirable in a future version of the model.

Budget calculations suggest that vertical advection of ice number due to the grid-box average vertical velocity could potentially play a role for upper tropospheric ice numbers.
The relative importance of this process in the model, however, most likely depends on the ice nucleation formulation. The NEW run exhibits larger biases in short and long-wave radiation in the southern ocean, which might be related to the representation of aerosol-ice interactions. In particular, there is little aerosol other than sea-salt simulated to exist in this region. A significant bias in outgoing long-wave radiation flux the tropics, on the other hand, is slightly reduced in the NEW run by reducing the detrainment of ice from the deep convection parameterization.

The radiative flux perturbation $(\mathrm{RFP}=\Delta \mathrm{SWABS}-\Delta \mathrm{OLR})$ related to anthropogenic aerosols (here defined as difference in net radiation at the top of the atmosphere between a 5year integration for present-day (PDA, year 2000) and a 5year integration for pre-industrial (PIA, year 1860) aerosols at fixed present-day SSTs and greenhouse gas concentrations in both runs, see Haywood et al., 2009; Lohmann et al., 2010) is $-1.59 \mathrm{~W} \mathrm{~m}^{-2}$ for the BASE and $-1.68 \mathrm{~W} \mathrm{~m}^{-2}$ for the NEW run. The perturbation in short-wave absorption is $-1.71 \mathrm{~W} \mathrm{~m}^{-2}$ in the BASE run and $-1.99 \mathrm{~W} \mathrm{~m}^{-2}$ in the NEW run, while the change in outgoing long-wave radiation is $-0.12 \mathrm{~W} \mathrm{~m}^{-2}$ in the BASE run and $-0.31 \mathrm{~W} \mathrm{~m}^{-2}$ in the NEW run. The stronger decrease in OLR in the NEW run is independent of the influence of anthropogenic changes in sulfate on cirrus clouds and could possibly be offset if black carbon instead of dust were to be considered as immersion IN. The efficiency of soot as immersion IN is, however, not well established (Kärcher et al., 2007). While potentially important, the influence of aerosols on climate change via effects on the ice phase in clouds remains poorly understood and the numbers reported above are subject to uncertainties regarding heterogeneous nucleation.

An important disadvantage of the present model setup is the absence of a prognostic treatment of aerosol number. In general, mass and number concentrations of aerosols are determined by different processes. Coagulation, for example only changes number, but not mass. Nucleation of sulfuric acid at low temperatures increases the aerosol number, but does not necessarily have to be associated with a large increase in mass. Since droplet activation and ice nucleation are functions of aerosol number, a one moment (mass only) aerosol scheme is not ideal for coupling with two-moment microphysics. Furthermore, for the sake of estimating ice nucleation rates and droplet activation, an external mixing state of the aerosol (with the exception of hydrophilic black carbon) is assumed, while for calculating the direct radiative effect, sulfate, and black carbon are assumed to be internally mixed. These inconsistencies are to be addressed in a future version of the model. In order to further increase the physical realism of the model and to eventually also reduce key uncertainties related to aerosol-cloud interactions, it would be desirable to couple the two-moment microphysics scheme to a two-moment aerosol scheme in a future version of the model. In addition to providing the aerosol number concentrations required to calculate droplet activation and ice nucleation, 
this would also facilitate a more realistic treatment of aerosol scavenging and could provide a basis for treating droplet activation and heterogeneous ice nucleation in a more consistent framework.

Moreover, there is a significant need to further study the interactions between deep convection, ice microphysics, and radiation. In particular, it would be desirable to implement a consistent microphysics formulation into the deep convection parameterization. This would in principle also allow for a more realistic treatment of aerosol scavenging in convective clouds. Including an explicit treatment of ice supersaturation in deep convective clouds would also provide a basis for simulating realistic relative humidities in the upper troposphere, which are used as input to the ice nucleation parameterization. One advantage of the Donner et al. (2001) deep and Bretherton et al. (2004) shallow convection parameterizations presently implemented in the AM3 GCM is that they provide sub-grid scale vertical velocities, which are useful for parameterizing droplet activation and ice nucleation in a two-moment microphysics framework. At present, there is also an ongoing effort to include a new cloud cover scheme into the AM3 GCM which uses a joint PDF of sub-grid vertical velocity, temperature, and total water mixing ratio based on Golaz et al. (2002). It is planned to eventually couple this new cloud cover scheme with the two-moment microphysics modules used in the present study. Preliminary experiments with two-moment microphysics and a considerably less sophisticated cloud cover scheme based on a total water PDF which were conducted in the framework of the present study have yielded encouraging results, but also given an indication of uncertainties regarding the treatment of super-saturation over ice.

Fortunately, an increasing number of new in-situ, laboratory, and remote-sensing observations is becoming available. In combination with more comprehensive models that simulate the observed variables these observations are a prerequisite for better understanding cloud-climate and aerosolcloud interactions and thereby for reducing some of the key uncertainties in climate projections.

\section{Appendix A}

\section{Modified Tompkins' (2007) scheme}

In contrast to Tompkins et al. (2007), we assume the change in cloud cover (Eq. 9) and in hydrometeor mixing ratio in the newly formed cloudy fraction of the grid box (second term in Eq. 10) to depend on $\left.\partial_{t}\left(\mathrm{RH}_{c} q_{s}\right)\right|_{l s}$ instead of $\left.\partial_{t} q_{s}\right|_{l s}$, where $\partial_{t} \equiv \partial / \partial t$. Other than that, the following derivations are similar to those described in Jakob (2000), and the implementation of Tompkins' (2007) scheme into the AM3 GCM to some extent builds on the existing implementation of the Tiedtke (1993) scheme. Since the specific humidity in the cloud free part of the grid box is assumed to be distributed

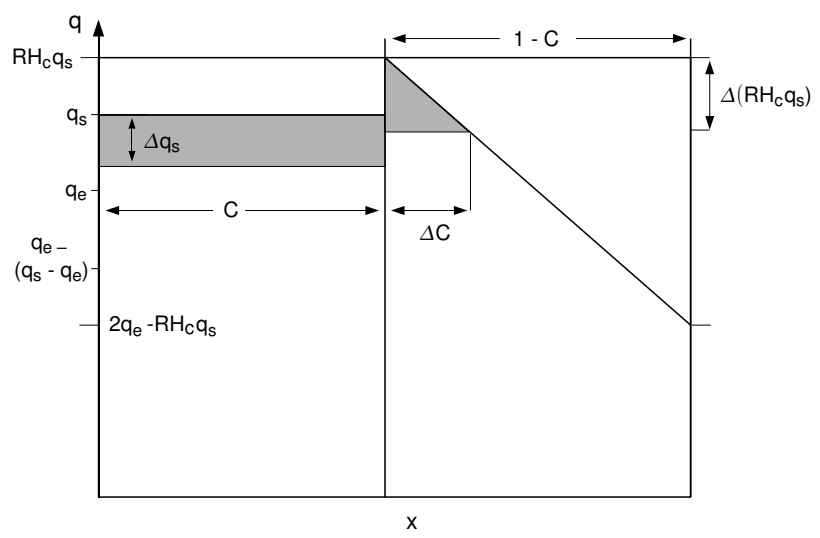

Fig. A1. Schematic: Partially cloud covered grid box with new cloud formation caused by a change in saturation vapor pressure $\left(\Delta q_{s}\right)$ and under certain conditions also critical relative humidity $\mathrm{RH}_{C}$ (see text). $\mathrm{C}$ denotes the cloudy fraction and (1-C) the cloud free fraction of the grid box at the beginning of the time step. Specific humidity $(q)$ equals saturation specific humidity $\left(q_{s}\right)$ in the cloudy part of the grid box and is assumed to be uniformly distributed around the environmental value $q_{e}$ in the cloud free part of the grid box (diagonal line). Shaded areas represent increases in condensate mixing ratio due to a change in $q_{s}$. Adapted from Jakob (2000).

uniformly around the environmental specific humidity $\left(q_{e}\right)$ between $\mathrm{RH}_{c} q_{s}$ and $q_{e}-\left(\mathrm{RH}_{c} q_{s}-q_{e}\right)$, Eq. (9) can be inferred from a simple triangle similarity in Fig. A1:

$$
\frac{\Delta C}{-\left.\Delta\left(\mathrm{RH}_{c} q_{s}\right)\right|_{l s}}=\frac{(1-C)}{2\left(\mathrm{RH}_{c} q_{s}-q_{e}\right)},
$$

or:

$\Delta C=\left.\frac{-(1-C)}{2\left(\mathrm{RH}_{c} q_{s}-q_{e}\right)} \Delta\left(\mathrm{RH}_{c} q_{s}\right)\right|_{l s}$,

where $\Delta C$ is the change in cloud cover associated with a change in $\mathrm{RH}_{c} q_{s}$. (Eq. (9) follows by taking the limit of infinitesimally small changes). The increase in condensate due to in-cloud condensation is given by $-\left.C \Delta q_{s}\right|_{l s}$, while the increase in condensate associated with an increase in cloud cover is $-\left.\frac{\Delta C}{2} \Delta\left(\mathrm{RH}_{c} q_{s}\right)\right|_{l s}$ (shaded areas in Fig. A1, compare Eq. 10).

In analogy to the GAMDT04 implementation of the Tiedtke (1993) scheme, expressions for the time derivatives $\left.\partial_{t} q_{s}\right|_{l s}$ and $\left.\partial_{t}\left(\mathrm{RH}_{c} q_{s}\right)\right|_{l s}$ in Eqs. (9) and (10) are derived from:

$$
\left.\partial_{t} q_{s}\right|_{l s}=\left.\left(\frac{\tilde{\omega}}{\rho c_{p}}+\left.\partial_{t} T\right|_{t, r}-\frac{L}{c_{p}} \partial_{t}\left(q_{l}+q_{i}\right)\right) \frac{\partial q_{s}}{\partial T}\right|_{p}
$$

and

$$
\begin{aligned}
& \left.\partial_{t}\left(\mathrm{RH}_{c} q_{s}\right)\right|_{l s}= \\
& \left.\quad\left(\frac{\tilde{\omega}}{\rho c_{p}}+\left.\partial_{t} T\right|_{t, r}-\frac{L}{c_{p}} \partial_{t}\left(q_{l}+q_{i}\right)\right) \frac{\partial\left(\mathrm{RH}_{c} q_{s}\right)}{\partial T}\right|_{p}
\end{aligned}
$$


and $\tilde{\omega}=\omega+g M_{c}$ is the vertical velocity outside deep convective updrafts diagnosed from the grid box mean vertical velocity $\omega$ and the deep convective mass flux $M_{c}, g$ is the gravity constant, $\left.\partial_{t} T\right|_{t, r}$ is the combined temperature tendency due to turbulence and radiation, $-L c_{p}^{-1} \partial_{t}\left(q_{l}+q_{i}\right)$ is the contribution from condensation/freezing, and $\partial q_{s} /\left.\partial T\right|_{p}$ and $\partial\left(\mathrm{RH}_{c} q_{s}\right) /\left.\partial T\right|_{p}$ are the time derivatives at constant pressure of $q_{s}$ and $\mathrm{RH}_{c} q_{s}$, respectively. For $T \geq-40^{\circ} \mathrm{C}, L$ represents the latent heat of evaporation, and for $T<-40^{\circ} \mathrm{C}, L$ represents the latent heat of sublimation.

Combining Eqs. (A3) and (10) yields:

$\left.\partial_{t} q_{s}\right|_{l s}=\frac{\left.\partial_{t} q_{s}\right|_{\mathrm{dry}}-\left.\left.\gamma \frac{\Delta t}{2} \partial_{t} C\right|_{l s} \partial_{t}\left(\mathrm{RH}_{c} q_{s}\right)\right|_{l s}}{1+\gamma C}$

where $\left.\partial_{t} q_{s}\right|_{\text {dry }}$ is the time derivative of $q_{s}$ if no condensation occurred in the grid box:

$\left.\partial_{t} q_{s}\right|_{\mathrm{dry}}=\left.\left(\frac{\tilde{\omega}}{\rho c_{p}}+\left.\partial_{t} T\right|_{t, r}\right) \frac{\partial q_{s}}{\partial T}\right|_{p}$

and

$\gamma=\left.\frac{L}{c_{p}} \frac{\partial q_{s}}{\partial T}\right|_{p}$.

For $\left.\partial_{t}\left(\mathrm{RH}_{c} q_{s}\right)\right|_{l s}$, the following expression is obtained by combining Eqs. (A4), (10), and (A5):

$\left.\partial_{t}\left(\mathrm{RH}_{c} q_{s}\right)\right|_{l s}=\frac{\left.(1+\gamma C) \partial_{t}\left(\mathrm{RH}_{c} q_{s}\right)\right|_{\mathrm{dry}}-\left.\beta C \partial_{t} q_{s}\right|_{\mathrm{dry}}}{1+\gamma C+\left.\beta \frac{\Delta t}{2} \partial_{t} C\right|_{l s}}$

where $\left.\partial_{t}\left(\mathrm{RH}_{c} q_{s}\right)\right|_{\text {dry }}$ is defined as:

$\left.\partial_{t}\left(\mathrm{RH}_{c} q_{s}\right)\right|_{\mathrm{dry}}=\left.\left(\frac{\tilde{\omega}}{\rho c_{p}}+\left.\partial_{t} T\right|_{t, r}\right) \frac{\partial\left(\mathrm{RH}_{c} q_{s}\right)}{\partial T}\right|_{p}$

and

$\beta=\left.\frac{L}{c_{p}} \frac{\partial\left(\mathrm{RH}_{c} q_{s}\right)}{\partial T}\right|_{p}$.

Combining Eqs. (A7) and (9) yields a quadratic equation for $\left.\partial_{t}\left(\mathrm{RH}_{c} q_{s}\right)\right|_{l s}$, which can be solved after calculating $\left.\partial_{t} q_{s}\right|_{\text {dry }}$ and $\left.\partial_{t}\left(\mathrm{RH}_{c} q_{s}\right)\right|_{\text {dry }}$ from Eqs. (A6) and (A8). In practice, we first compute $\partial q_{s} /\left.\partial T\right|_{p}$ and $\partial\left(\mathrm{RH}_{c} q_{s}\right) /\left.\partial T\right|_{p}$, then $\left.\partial_{t} q_{s}\right|_{\text {dry }}$ and $\left.\partial_{t}\left(\mathrm{RH}_{c} q_{s}\right)\right|_{\text {dry }}$, and then solve the quadratic equation for $\left.\partial_{t}\left(\mathrm{RH}_{c} q_{s}\right)\right|_{l_{s}}$. The result is used to estimate $\left.\partial_{t} C\right|_{l s}$ from Eq. (9). Subsequently, the prognostic equation for cloud cover,

$\partial_{t} C=\left.(1-C) \partial_{t} C\right|_{l s}-\left.C \partial_{t} C\right|_{e r}$,

which includes contributions from large-scale condensation (Eq. 9) and cloud erosion (Eq. 12) is integrated analytically as suggested by Tiedtke (1993). In the next step, $\left.\partial_{t} q_{s}\right|_{l s}$ is diagnosed from Eq. (A5) and the change in condensate is computed from:

$\left.\partial_{t}\left(q_{l}+q_{i}\right)\right|_{\text {strat }}=-\left.C \partial_{t} q_{s}\right|_{l s}-\left.\frac{\Delta t}{2} \partial_{t} C \partial_{t}\left(\mathrm{RH}_{c} q_{s}\right)\right|_{l s}$, where (unlike in Eq. 10) $\partial_{t} C$ includes the contribution from erosion. Finally, the condensation rate is adjusted to avoid super-saturation at the end of the timestep (Eq. 11) and then passed to the microphysics module, where the final phase partitioning of this rate is calculated. The $q_{l}$ and $q_{i}$ erosion tendencies given by Eq. (12) are also passed to the microphysics module and applied together with the microphysical tendencies.

A somewhat similar method is also applied in the AM3 GCM, although important differences exist, such as the order of operations in performing the saturation adjustment (Sect. 2.3). In particular, an equation similar to Eq. (A3) is also applied in the AM3 GCM, which is less computationally expensive than the iterative adjustment used in the original Tiedtke (1993) scheme.

Above $238.15 \mathrm{~K}, \mathrm{RH}_{c}$ is assumed to be independent of temperature, and either 1 or 1.2 (as described in Sect. 2.2.2). Below $238.15 \mathrm{~K}$, we assume $\mathrm{RH}_{c}=1.2$ when heterogeneous nucleation involving dust takes place, which is close to $\mathrm{RH}_{\text {het }}$ in Eq. (14). Under homogeneous freezing conditions the temperature derivative $\partial\left(\mathrm{RH}_{c} q_{s}\right) /\left.\partial T\right|_{p}$ is estimated from:

$\left.\frac{\partial\left(\mathrm{RH}_{c} q_{s}\right)}{\partial T}\right|_{p}=\mathrm{RH}_{c} \frac{L q_{s}}{R_{v} T^{2}}+q_{s}\left(2 A T_{c}+B\right)$

where $R_{v}=461.5 \mathrm{~J} \mathrm{~kg}^{-1} \mathrm{~K}^{-1}$ is the gas constant for water vapor, and $A=6.6 \times 10^{-3}$ and $B=1.052$ based on Liu et al. (2007) (see also Eq. (13) above). Terms that depend on vertical velocity as well as temperature in Eq. (13), and which are significantly smaller than the terms that only depend on temperature, are currently neglected in computing $\partial \mathrm{RH}_{c} / \partial T$.

Note that for a given constant (temperature independent) $\mathrm{RH}_{c} \neq 1$, the scheme described here would still differ from the original Tompkins et al. (2007) scheme.

\section{Appendix B}

\section{List of symbols and acronyms}

$\partial_{t} \quad \partial / \partial t$ (partial derivative w.r.t. time)

$\Gamma \quad$ Euler Gamma function

$\Delta t \quad$ integration time step

$\Delta z \quad$ vertical grid spacing in meters

$\eta \quad$ relative radius dispersion of hydrometeor size distribution

$\lambda$ slope parameter of hydrometeor size distribution

$\mu \quad$ spectral shape parameter of hydrometeor size distribution

$\rho_{w} \quad$ density of water

$\sigma_{w} \quad$ variance of the sub-grid scale vertical velocity PDF

$\sigma_{\min }$ minimum variance of the sub-grid scale vertical velocity PDF

AIRS Atmospheric infrared sounder

AM3 GFDL Atmospheric Model version 3

AOD aerosol optical depth 
AR5 5th Assessment Report (IPCC)

BC black carbon

C cloudy fraction of the model grid box

CAM3 Community Atmosphere Model version 3

$\mathrm{CCN}$ cloud condensation nuclei

CMAP CPC Merged Analysis of Precipitation

CPC Climate Prediction Center (NOAA)

$c_{\mu} \quad$ empirical constant in Kolmogorov-Prandtl expression

$D$ diameter

$\mathrm{DU}_{2.5}$ mass concentration of dust particles with $D<2.5 \mu \mathrm{m}$

$\mathrm{DU}_{2.5}^{*}$ reference surface dust concentration

$D_{g \text {,dry }}$ geometric mean diameter of dry aerosol

$D_{\mathrm{vi}}$ volume mean diameter of ice particles

E1 large-scale evaporation term (Tiedtke, 1993)

$f_{\text {adi }}$ fraction of ice detrained from deep convective anvils

FISH Fast in-situ Stratospheric Hygrometer

FSSP Forward Scattering Spectrometer Probe

GAMDT GFDL Global Atmospheric Model Development Team

GAMDT04 GFDL Global Atmospheric Model Development Team (2004)

GCM general circulation model

GFDL Geophysical Fluid Dynamics Laboratory

GPCP Global Precipitation Climatology Project

IN ice nuclei

IPCC Intergovernmental Panel on Climate Change

ISCCP International Satellite Cloud Climatology Project

IWC ice water content

IWP ice water path

$k_{1} \quad$ ratio of effective to volume mean radius in the BASE scheme

$k_{2}$ ratio of effective to volume mean radius in the NEW scheme

$k_{e r}$ Tiedtke's "erosion coefficient"

$K_{T}$ mixing coefficient for heat

$L \quad$ latent heat of evaporation $\left(T \geq-40^{\circ} \mathrm{C}\right) / \operatorname{sublimation}(T<-$ $40^{\circ} \mathrm{C}$ )

$L_{m} \quad$ mean maximum dimension of ice crystals

LWC liquid water content

LWCF long-wave cloud forcing

LWP liquid water path

MODIS Moderate Resolution Imaging Spectroradiometer

MOZAIC Measurement of ozone on Airbus in-service aircraft

MG08 Morrison and Gettelman (2008)

netradTOA net radiation at the top of the atmosphere

$N_{0} \quad$ intercept parameter in hydrometeor size distribution

$N_{i} \quad$ grid-box average ice particle number

$N_{i, d}^{*} \quad$ maximum number of ice crystals due to deposition nucleation

$N_{i, \text { nuc }}^{*}$ maximum number of ice crystals from ice nucleation parametrization

$N_{l, \text { act }}^{*}$ maximum number of droplets that can be activated

$N_{l, n}(w)$ number of droplets activated at vertical velocity $w$

$N_{l} \quad$ grid-box average droplet number

$N_{l}^{\prime} \quad$ in-cloud droplet number
$N_{l C}^{\prime} \quad$ column-integrated $N_{l}^{\prime}$

$N_{l}^{\prime \prime} \quad$ in-cloud droplet number in units of $\mathrm{cm}^{-3}$

NOAA National Oceanic and Atmospheric Administration

OC organic carbon

OLR outgoing long-wave radiation

OM organic matter

$P_{\text {conv }}$ surface precipitation due to convective clouds

$P_{\text {strat }}$ surface precipitation due to stratifrom clouds

$P_{\text {tot }}$ total surface precipitation

PDF probability density function

$q_{e} \quad$ clear sky "environmental" vapor mixing ratio

$q_{i} \quad$ grid-box average ice particle mass mixing ratio (not including snow)

$q_{l} \quad$ grid-box average (liquid) droplet mass mixing ratio

$q_{l}^{\prime} \quad$ in-cloud (liquid) droplet mixing ratio

$q_{s} \quad$ saturation vapor mixing ratio w.r.t. liquid water for $T \geq 250 \mathrm{~K}$ and w.r.t. ice $T<250 \mathrm{~K}$.

$q_{v} \quad$ vapor mixing ratio

$q_{v}^{\max }$ maximum allowed grid-mean specific humidity

$r_{\text {eff }}$ effective radius

$r_{v} \quad$ volume mean radius

RH relative humidity w.r.t. liquid water for $T \geq 250 \mathrm{~K}$ and w.r.t. ice $T<250 \mathrm{~K}$.

$\mathrm{RH}_{c}$ critical RH (see Sect. 2.2.2, below Eq. 9)

$\mathrm{RH}_{e}$ grid box environmental (clear sky) $\mathrm{RH}$

$\mathrm{RH}_{e}$,ice $\mathrm{RH}_{e}$, but w.r.t. ice

$\mathrm{RH}_{\text {hom }}$ critical RH w.r.t. ice for homogeneous nucleation

$\mathrm{RH}_{\text {het }}$ critical $\mathrm{RH}$ w.r.t. ice for immersion nucleation

$r_{v} \quad$ volume mean radius

$S_{i} \quad S_{i}=\mathrm{RH}_{e, \text { ice }}-1$

SOA Secondary organic aerosols

SSM/I Special Sensor Microwave/Imager

SST sea surface temperature

SWABS short-wave absorption

SWCF short-wave cloud forcing

$T$ temperature in Kelvin

$T_{C} \quad$ temperature in degree Celsius

TCC total cloud cover

TIROS Television Infrared Observation Satellites

TOVS TIROS Operational Vertical Sounder

TWC total water content

$w \quad$ vertical velocity

WBF Wegener-Bergeron-Findeisen (mechanism)

Acknowledgements. We thank Frank Li and Duane Waliser for providing CloudSat IWP datasets. Xiaohong Liu, Yanluan Lin, Adrian Tompkins, Johannes Quaas, Charles Seman, Vaishali Naik, Huan Guo, and several others have contributed by valuable discussions on various aspects of this study. Furthermore, we appreciate the very insightful comments by two anonymous referees. CERES-EBAF data were obtained from the NASA Langley Research Center EOSDIS Distributed Active Archive Center. Marc Salzmann was supported under award NA08OAR4320752 from the National Oceanic and Atmospheric Administration, US Department of Commerce. The statements, findings, conclusions, and recommendations are those of the authors and do not necessarily reflect the views of the National Oceanic and Atmospheric Administration, or the US Department of Commerce.

Edited by: J. Quaas 


\section{References}

Abdul-Razzak, H. and Ghan, S. J.: A parameterization of aerosol activation 2. Multiple aerosol types, J. Geophys. Res., 105, 6837-6844, 2000.

Ackerman, A. S., Kirkpatrick, M. P., Stevens, D. E., and Toon, O. B.: The impact of humidity above stratiform clouds on indirect aerosol climate forcing, Nature, 432, 1014-1017, 2004.

Adler, R. F., Huffman, G. J., Chang, A., Ferraro, R., Xie, P.-P., Janowiak, J., Rudolf, B., Schneider, U., Curtis, S., Bolvin, D., Gruber, A., Susskind, J., Arkin, P., and Nelkin, E.: The Version2 Global Precipitation Climatology Project (GPCP) monthly precipitation analysis (1979-Present), J. Hydrometeorology, 4, 1147-1167, 2003.

Albrecht, B. A.: Aerosols, cloud microphysics, and fractional cloudiness, Science, 245, 1227-1230, 1989.

Altaratz, O., Koren, I., Reisin, T., Kostinski, A., Feingold, G., Levin, Z., and Yin, Y.: Aerosols' influence on the interplay between condensation, evaporation and rain in warm cumulus cloud, Atmos. Chem. Phys., 8, 15-24, doi:10.5194/acp-8-152008, 2008.

Andreae, M. O., Jones, C. D., and Cox, P. M.: Strong present-day aerosol cooling implies a hot future, Nature, 435, 1187-1190, 2005.

Andres, R. J. and Kasgnoc, A. D.: A time-averaged inventory of subaerial volcanic sulfur emissions, J. Geophys. Res., 103, 25251-25261, 1998.

Austin, R. T., Heymsfield, A. J., and Stephens, G. L.: Retrieval of ice cloud microphysical parameters using the CloudSat millimeter-wave radar and temperature, J. Geophys. Res., 114, D00A23, doi:10.1029/2008JD010049, 2009.

Barahona, D. and Nenes, A.: Parameterization of cirrus cloud formation in large-scale models: Homogeneous nucleation, J. Geophys. Res., 113, D11211, doi:10.1029/2007JD009355, 2008.

Berezinskiy, N. A., Stepanov, G. V., and Khorguani, V. G.: Altitude variation of relative ice-forming activity of natural aerosol, S. Meterol. Hydrol., 12, 86-89, 1986.

Bigg, E. K.: The supercooling of water, Proc. Phys. Soc. London, 66B, 688-694, 1953.

Bower, K. N. and Choularton, T. W.: A parameterisation of the effective radius of ice free clouds for use in global climate models, Atmos. Res., 27, 305-339, 1992.

Brenguier, J. L., Pawlowska, H., and Schüller, L.: Cloud microphysical and radiative properties for parameterization and satellite monitoring of the indirect effect of aerosol on climate, J. Geophys. Res., 108, 8632, doi:10.1029/2002JD002682, 2003.

Bretherton, C. S., McCaa, J. R., and Grenier, H.: A new parameterization for shallow cumulus convection and its application to marine subtropical cloud-topped boundary layers. Part I: Description and 1D results, Mon. Weather Rev., 132, 864-882, 2004.

Cziczo, D. J., Murphy, D. M., Hudson, P. K., and Thomson, D. S.: Single particle measurements of the chemical composition of cirrus ice residue during CRYSTAL-FACE, J. Geophys. Res., 109, D04201, doi:10.1029/2003JD004032, 2004.

DeMott, P. J., Rogers, R. C., and Kreidenweis, S. M.: The susceptability of ice formation in upper tropospheric clouds to insoluble aerosol components, J. Geophys. Res., 102, 19575-19584, 1997.

Diehl, K. and Wurzler, S.: Heterogeneous drop freezing in the immersion mode: Model calculations considering soluble and insoluble particles in the drops, J. Atmos. Sci., 61, 2063-2072,
2004.

Donner, L. J.: A cumulus parameterization including mass fluxes, vertical momentum dynamics, and mesoscale effects, J. Atmos. Sci., 50, 889-906, 1993.

Donner, L. J., Seman, C. J., Soden, B. J., Hemler, R. S., Warren, J. C., Ström, J., and k. N. Liou: Larce-scale ice clouds in the GFDL SKYHI general circulation model, J. Geophys. Res., 102, 21745-21768, 1997.

Donner, L. J., Seman, C. J., and Hemler, R. S.: A cumulus parameterization including mass fluxes, convective vertical velocities, and mesoscale effects: Thermodynamic and hydrological aspects in a General Circulation Model, J. Clim., 14, 3444-3463, 2001.

Donner, L. J., Wyman, B. L., Hemler, R. S., Horrowitz, L. W., Ming, Y., Zhao, M., Golaz, Ginoux, P., Lin, S.-J., Schwarzkopf, M. D., J.-C., Austin, J., Alaka, G., Cooke, W. F.,Delworth, T. L., Freidenreich, S. M., Gordon, C. T., Griffies, S., Held, I. M., Hurlin, W. J., Klein, S. A., Knutson, T. R., Langenhurst, A. R., Lee, H.C., Lin, Y., Magi, B. I., Maleyshev, S. L., Milly, P. C. D., Naik, V., Nath, M. J., Pincus, R., Polshay, J. J., Ramaswamy, V., Seman, C. J., Shevliakova, E., Sirutis, J. J., Stern, W. F., Stouffer, R. J., Wilson, R. J., Winton, M., Wittenberg, A. T., and Zheng, F.: The dynamical core, physical parameterizations, and basic simulation characteristics of the atmospheric component of the GFDL global coupled model CM3, J. Climate, submitted, 2010.

$\mathrm{Fu}, \mathrm{Q}$.: An accurate parameterization of the solar radiative properties of cirrus clouds for climate models, J. Climate, 9, 20582028, 1996.

Fu, Q. and Liou, K. N.: Parameterization of the radiative properties of cirrus clouds, J. Atmos. Sci., 50, 2008-2025, 1993.

$\mathrm{Fu}$, Q., Krueger, S. K., and Liou, K. N.: Interactions of radiation and convection in simulated tropical cloud clusters, J. Atmos. Sci., 52, 1310-1328, 1995.

Georgii, H. W. and Kleinjung, E.: Relations between the chemical composition of atmospheric aerosol particles and the concentration of natural ice nuclei, J. Rech. Atmos., 3, 145-156, 1967.

Gettelman, A., Fetzer, E. J., Eldering, A., and F. W, I.: The global distribution of supersaturation in the upper troposphere from the Atmospheric Infrared Sounder, J. Climate, 19, 6089-6103, 2006.

Gettelman, A., Morrison, H., and Ghan, S. J.: A new two-moment bulk stratiform cloud microphysics scheme in the community atmosphere model, version 3 (CAM3). Part II: Single-colunm and global results, J. Climate, 21, 3660-3679, 2008.

GFDL Global Atmospheric Model Development Team: The new GFDL global atmosphere and land model AM2-LM2: Evaluation with prescribed SST simulations, J. Atmos. Chem., 17, 4641-4673, 2004.

Ghan, S. J., Leung, L. R., Easter, R. C., and Abdul-Razzak, H.: Prediction of cloud droplet number in a general circulation model, J. Geophys. Res., 102, 21777-21794, 1997.

Gierens, K., Schumann, U., Helten, M., Smit, H., and Marenco, A.: A distribution law for relative humidity in the upper troposphere and lower stratosphere derived from three years of MOZAIC measurements, Annales Geophysicae, 17, 1218-1226, 1999.

Golaz, J.-C., Larson, V. E., and Cotton, W. R.: A PDF-based model for boundary layer clouds. Part I: Method and model description, J. Atmos. Sci., 59, 3540-3551, 2002.

Golaz, J.-C., Salzmann, M., Donner, L. J., Horowitz, 1. W., Ming, Y., and Zhao, M.: Sensitivity to upscaling assumptions of the subgrid cloud drop activation in the GFDL AM3 GCM, J. Cli- 
mate, submitted, 2010.

Greenwald, T. J., Stephens, G. L., Haar, T. H. V., and Jackson, D. L.: A physical retrieval of cloud liquid water over the global Oceans using Special Sensor Microwave/Imager (SSM/I) observations, J. Geophys. Res., 98, 18471-18488, 1993.

Hansen, J., Nazarenko, L., Ruedy, R., Sato, M., Willis, J., Genio, A. D., Koch, D., Lacis, A., Lo, K., Menon, S., Novakov, T., Perlwitz, J., Russell, G., Schmidt, G. A., and Tausnev, N.: Earth's Energy Imbalance: Confirmation and Implications, Science, 308, 1431-1435, doi:10.1126/science.1110252, http:// www.sciencemag.org/cgi/content/abstract/308/5727/1431, 2005.

Haywood, J., Donner, L., Jones, A., and Golaz, J.-C.: Global indirect radiative forcing caused by aerosols: IPPC (2007) and beyond, In: Clouds in the perturbed climate system: their relationship to energy balance, atmospheric dynamics, and precipitation, edited by: Heintzenberg, J. and Charlson, R. J., MIT Press, 451467, 2009.

Heymsfield, A. J.: On measurements of small ice particles in clouds, Geophys. Res. Lett., 34, L23812, doi:10.1029/2007GL030951, 2007.

Heymsfield, A. J. and Donner, L. J.: A scheme for parameterizing ice-cloud water-content in general circulation models., J. Atmos. Sci., 47, 1865-1877, 1990.

Hoose, C., Lohmann, U., Edin, R., and Tegen, I.: Global influence of dust mineralogical composition on heterogeneous ice nucleation in mixed-phase clouds., Environ. Res. Lett., 3, 025003, doi:10.088/1748-9326/3/2/025003, 2008a.

Hoose, C., Lohmann, U., Stier, P., Verheggen, B., and Weingartner, E.: Aerosol processing in mixed-phase clouds in ECHAM5HAM: Model description and comparison to observations, J. Geophys. Res., 113, D07210, doi:10.1029/2007JD009251, 2008b.

Horowitz, L. W., Walters, S., Mauzerall, D. L., Emmons, L. K., Rasch, P. J., Garnier, C., Tie, X., Lamarque, J.-F., Schultz, M. G., Tyndall, G. S., Orlando, J. J., and Brasseur, G. P.: A global simulation of tropospheric ozone and related tracers: Description and evaluation of MOZART, version 2, J. Geophys. Res., 108, 4728, doi:10.1029/2002JD002853, 2003.

IPCC: Climate change 2007: The physical science basis. Contribution of Working Group I to the Fourth Assessment Report of the Intergovernmental Panel on Climate Change, edited by: Solomon, S., Qin, D., Manning, M., Chen, Z., Marquis, M. Aceryt, K. B., Tignor, M. and Miller, H. L., Cambridge University Press, Cambridge, UK and New York, NY, USA, 996 pp., 2007.

Jakob, C.: The representation of cloud cover in atmospheric general circulation models, Ph.D. thesis, Ludwig-MaximiliansUniversität, München, Munich, Gemany, available at http:// users.monash.edu.au/ $\sim$ cjakob/Papers/thesis_cjakob.pdf, 2000.

Jakob, C. and Klein, S. A.: A parameterization of the effects of cloud and precipitation overlap for use in general circulation models, Q. J. Roy. Meteorol. Soc., 126, 2525-2544, 2000.

Jiang, H., Xue, H., Teller, A., Feingold, G., and Levin, Z.: Aerosol effects on the lifetime of shallow cumulus, Geophys. Res. Lett., 33, L14806, doi:1029/2006GL026024, 2006.

Kärcher, B. and Ström, J.: The roles of dynamical variability and aerosols in cirrus cloud formation, Atmos. Chem. Phys., 3, 823838, doi:10.5194/acp-3-823-2003, 2003.

Kärcher, B., Möhler, O., DeMott, P. J., Pechtl, S., and Yu, F.: Insights into the role of soot aerosols in cirrus cloud formation, At- mos. Chem. Phys., 7, 4203-4227, doi:10.5194/acp-7-4203-2007, 2007.

Kessler, E.: On the distribution and continuity of water substance in atmospheric circulation, in: Meteor. Monogr., No. 32, Amer. Meteor. Soc., 84 pp., 1969.

Khairoutdinov, M. and Kogan, Y.: A new cloud physics parameterization in a large-eddy simulation model of marine stratocumulus, Mon. Weather Rev., 128, 229-243, 2000.

Koop, T., Ng, H. P., Molina, L. T., and Molina, M. J.: A new optical technique to study aerosol phase transitions: The nucleation of ice from $\mathrm{H}_{2} \mathrm{SO}_{4}$ aerosols, J. Phys. Chem., 102A, 8924-8931, 1998.

Koop, T., Luo, B., Tsias, A., and Peter, T.: Water activity as the determinant for homogeneous ice nucleation in aqueous solutions, Nature, 406, 611-614, 2000.

Korolev, A. V.: Limitations of the Wegener-Bergeron-Findeisen mechanism in the evolution of mixed-phase clouds, J. Atmos. Sci., 64, 3372-3375, 2007.

Korolev, A. V., Isaac, G. A., Cober, S. G., Strapp, J. W., and Hallett, J.: Microphysical characterization of mixed-phase clouds, Q. J. Roy. Meteorol. Soc., 129, 39-65, 2003.

Krämer, M., Schiller, C., Afchine, A., Bauer, R., Gensch, I., Mangold, A., Schlicht, S., Spelten, N., Sitnikov, N., Borrmann, S., de Reus, M., and Spichtinger, P.: Ice supersaturations and cirrus cloud crystal numbers, Atmos. Chem. Phys., 9, 3505-3522, doi:10.5194/acp-9-3505-2009, 2009.

Kristjánsson, J. E., Edwards, J. M., and Mitchell, D. L.: Impact of a new scheme for optical properties of ice crystals on climates of two GCMs, J. Geophys. Res., 105, 10063-10079, 2000.

Lamarque, J.-F., Granier, C., Bond, T., Eyring, V., Heil, A., Kainuma, M., Lee, D., Liousse, C., Mieville, A., Riahi, K. Schultz, M., Smith, S., Stehfest, E., Stevenson, D., Thomson, A., Aardenne, J. V., and Vuuren, D. V.: Gridded emissions in support of IPCC AR5, IGAC Newsletter, 41, 12-18, 2009.

Li, J.-L. F., Waliser, D., Woods, C., Teixeira, J., Bacmeister, J., Chern, J., Shen, B. W., Tompkins, A., Tao, W. K., and Kohler, M.: Comparisons of satellites liquid water estimates to ECMWF and GMAO analyses, 20th century IPCC AR4 climate simulations, and GCM simulations, J. Geophys. Res., 35, L19710, doi:10.1029/2008GL035427, 2008.

Liu, X. and Penner, J. E.: Ice nucleation parameterization for global models, Meteor. Z., 14, 499-514, 2005.

Liu, X., Penner, J. E., Ghan, S. J., and Wang, M.: Inclusion of ice microphysics in the NCAR community atmospheric model version 3 (CAM3), J. Climate, 20, 4526-4547, 2007.

Liu, X., Penner, J. E., and Wang, M.: Influence of anthropogenic sulfate and black carbon on upper tropospheric clouds in the NCAR CAM3 model coupled to the IMPACT global aerosol model, J. Geophys. Res., 114, D03204, doi:10.1029/2008JD010492, 2009.

Lock, A. P., Brown, A. R., Bush, M. R., Martin, G. M., and Smith, R. N. B.: A new boundary layer mixing scheme. Part I: Scheme description and single-column model tests, Mon. Weather Rev., 128, 3187-3199, 2000.

Loeb, N. G., Wielicki, B. A., Doelling, D. R., Smith, G. L., Keyes, D. F., Kato, S., Manalo-Smith, N., and Wong, T.: Toward Optimal Closure of the Earth's Top-of-Atmosphere Radiation Budget, J. Climate, 22, 748-766, 2009.

Lohmann, U.: A glaciation indirect aerosol effect caused 
by soot aerosols, Geophys. Res. Lett., 29, 1052, doi:10.1029/2001GL014 357, 2002.

Lohmann, U. and Diehl, K.: Sensitivity studies of the importance of dust ice nuclei for the indirect aerosol effect on stratiform mixedphase clouds, J. Atmos. Sci., 63, 968-982, 2006.

Lohmann, U. and Feichter, J.: Global indirect aerosol effects: a review, Atmos. Chem. Phys., 5, 715-737, doi:10.5194/acp-5-7152005, 2005.

Lohmann, U. and Kärcher, B.: First interactive simulations of cirrus clouds formed by heterogeneous freezing in the ECHAM general circulation model, J. Geophys. Res., 107, 4105, doi:10.1029/2001JD000767, 2007.

Lohmann, U., Kärcher, B., and Hendricks, J.: Sensitivity studies of cirrus clouds formed by heterogeneous freezing in the ECHAM GCM, J. Geophys. Res., 109, D16204, doi:10.1029/2003JD0004443, 2004.

Lohmann, U., Rotstayn, L., Storelvmo, T., Jones, A., Menon, S., Quaas, J., Ekman, A. M. L., Koch, D., and Ruedy, R.: Total aerosol effect: radiative forcing or radiative flux perturbation?, Atmos. Chem. Phys., 10, 3235-3246, doi:10.5194/acp-10-32352010, 2010.

Lohmann, U., Stier, P., Hoose, C., Ferrachat, S., Kloster, S., Roeckner, E., and Zhang, J.: Cloud microphysics and aerosol indirect effects in the global climate model ECHAM5-HAM, Atmos. Chem. Phys., 7, 3425-3446, doi:10.5194/acp-7-3425-2007, 2007.

Magi, B., Ginoux, P., Ming, Y., and Ramaswamy, V.: Evaluation of tropical and extratropical Southern Hemisphere African aerosol properties simulated by a climate model, J. Geophys. Res., 114, D14204, doi:10.1029/2008JD011128, 2009.

Manton, M. J. and Cotton, W. R.: Formulation of approximate equations for modeling moist deep convection on the mesoscale, Atmospheric Science Paper No. 266, Colorado State University, 62 pp., 1977.

Martin, G. M., Johnson, D. W., and Spice, A.: The measurement and parameterization of effective radius of droplets in warm stratocumulus clouds, J. Atmos. Sci., 51, 1823-1842, 1994.

McFarquhar, G. M. and Heymsfield, A. J.: Microphysical characteristics of three anvils sampled during the Central Equatorial Pacific Experiment, J. Atmos. Sci., 53, 2401-2423, 1996.

McFarquhar, G. M., Um, J., Freer, M., Baumgardner, D., Kok, G. L., and Mace, G.: Importance of small ice crystals to cirrus properties: Observations from the Tropical Warm Pool International Cloud Experiment (TWP-ICE), Geophys. Res. Lett., 34, L13803, doi:10.1029/2007GL029865, 2007.

Meyers, M. P., DeMott, P. J., and Cotton, W. R.: New primary ice nucleation parameterizations in an explicit cloud model, J. Appl. Meteorol., 32, 708-721, 1992.

Ming, Y., Ramaswamy, V., Donner, L. J., and Phillips, V. T. J.: A new parameterization of cloud droplet activation applicable to general circulation models, J. Atmos. Sci., 63, 1348-1356, 2006.

Ming, Y., Ramaswamy, V., Donner, L. J., Phillips, V. T. J., Klein, S. A., Ginoux, P. A., and Horowitz, L. W.: Modeling the interactions between aerosols and liquid water clouds with a selfconsistent cloud scheme in a general circulation model, J. Atmos. Sci., 64, 1189-1209, 2007.

Minikin, A., Petzold, A., Ström, J., Krejci, R., Seifert, M., van Velthoven, P., Schlager, H., and Schumann, U.: Aircraft observations of the upper tropospheric fine particle aerosol in the North- ern and Southern Hemispheres at midlatitudes, Geophys. Res. Lett., 30, 1503, doi:10.1029/2002GL016458, 2003.

Morrison, H. and Gettelman, A.: A new two-moment bulk stratiform cloud microphysics scheme in the community atmosphere model, version 3 (CAM3). Part I: Description and numerical tests, J. Climate, 21, 3642-3659, 2008.

Morrison, H. and Grabowski, W. W.: A novel approach for representing ice microphysics in models: Description and tests using a kinematic framework., J. Atmos. Sci., 65, 1528-1548, 2007.

Morrison, H., Curry, J. A., and Khvorostyanov, V. I.: A new doublemoment microphysics parameterization for application in cloud and climate models. Part I: Description, J. Atmos. Sci., 62, 1665$1677,2005$.

Pawlowska, H., Grabowski, W. W., and Brenguier, J.-L.: Observations of the width of cloud droplet spectra in stratocumulus, Geophys. Res. Lett., 33, L19810, doi:10.1029/2006GL026841, 2006.

Pincus, R., Hemler, R., and Klein, S. A.: Using stochastically generated subcolumns to represent cloud structure in a large-scle model, Mon. Weather Rev., 134, 3644-3656, 2006.

Putman, W. M. and Lin, S.-J.: Finite-volume transport on various cubed-sphere grids, J. Comput. Phys., 227, 55-78, 2007.

Rayner, N. A., Parker, D. E., Horton, E. B., Folland, C. K., Alexander, L. V., Rowell, D. P., Kent, E. C., and Kaplan, A.: Global analyses of sea surface temperature, sea ice, and night marine air temperature since the late nineteenth century, J. Geophys. Res. 108, 4407, doi:10.1029/2002JD002670, 2003.

Remer, L. A., R, G. K., R, C. L., Kaufman, Y. L., Tanre, D., Mattoo, S., Vanderlei Martins, J., Ichoku, C., Koren, I., Yu, H., and Holben, B. N.: Global aerosol climatology from the MODIS satellite sensors, J. Geophys. Res., 113, D14S07, doi:10.1029/2007JD009661, 2008.

Rodi, W.: Turbulence models and their application in hydraulics. A state-of-the-art review. 3rd edn, A. A. Balkema, Rotterdam, The Netherlands, 1993.

Rossow, W. B. and Schiffer, R. B.: Advances in understanding clouds from ISCCP, B. Am. Meteorol. Soc., 80, 2261-2287, 1999.

Rotstayn, L. D.: A physically based scheme for the treatment of stratiform clouds and precipitation in large-scale models. I: Description and evaluation of the microphysical processes, Q. J. Roy. Meteorol. Soc., 123, 1227-1282, 1997.

Rotstayn, L. D., Ryan, B. F., and Katzfey, J. J.: A scheme for calculation of the liquid faraction in mixed phase clouds in large-scale models, Mon. Weather Rev., 128, 1070-1088, 2000.

Ryan, B. F.: On the global variation of precipitating layer clouds, B. Am. Meteorol. Soc., 77, 53-70, 1996.

Scott, N. A., Chedin, A., Armante, R., Francis, J., Stubenrauch, C., Chaboureau, J. P., Chevallier, F., Claud, C., and Cheruy, F.: Characteristics of the TOVS pathfinder Path-B dataset, B. Am. Meteorol. Soc., 80, 2679-2701, 1999.

Seifert, A. and Beheng, K. D.: A double-moment parameterization for simulating autoconversion, accretion and selfcollection, Atmos. Res., 59, 265-281, 2001.

Slingo, J. M.: A GCM parameterization for the shortwave radiative properties of water clouds, J. Atmos. Sci., 46, 1419-1427, 1989.

Soden, B. J. and Held, I. M.: An assessment of climate feedbacks in coupled ocean-atmosphere models, J. Climate, 19, 3354-3360, 2006. 
Stephens, G. L., Vane, D. G., Tanelli, S., Im, E., Durden, S., Rokey, M., Reinke, D., Partain, P., Mace, G. G., Austin, R., L'Ecuyer, T., Haynes, J., Lebsock, M., Suzuki, K., Waliser, D., Wu, D., Kay, J., Gettelman, A., Wang, Z., and Marchand, R.: CloudSat mission: Performance and early science after the first year of operation, J. Geophys. Res., 113, D00A18, doi:10.1029/2008JD009 982, 2008.

Storelvmo, T., Kristjansson, J. E., and Lohmann, U.: Aerosol influence on mixed-phase clouds in CAM-Oslo, J. Atmos. Sci., 65, 3214-3230, 2008.

Susskind, J., Piraino, P., Rokke, L., Iredell, T., and Mehta, A.: Characteristics of the TOVS Pathfinder Path A dataset, B. Am. Meteorol. Soc., 78, 1449-1472, 1997.

Tiedtke, M.: Representation of clouds in large scale models, Mon. Weather Rev., 121, 3040-3061, 1993.

Tompkins, A. M., Gierens, K., and Rädel, G.: Ice supersaturation in the ECMWF integrated forecast system, Q. J. Roy. Meteorol. Soc., 133, 53-63, 2007.

Tsushima, Y., Emori, S., Ogura, T., Kimoto, M., Webb, M. J., Williams, K. D., Ringer, M. A., Soden, B. J., Li, B., and Andronova, N.: Importance of the mixed-phase cloud distribution in the control climate for assessing the response of clouds to carbon dioxide increase: a multi-model study, Clim. Dynam., 27, 113-116, 2006.

Twomey, S.: Pollution and the planetary albedo, Atmos. Environ., 8, 1251-1256, 1974.

Waliser, D. E., Li, J., Woods, C. P., Austin, R. T., Bacmeister, J., Chern, J., Genio, A. D., Jiang, J. H., Kuang, Z., Meng, H., Minnis, P., Platnick, S., Rossow, W. B., Stephens, G. L., SunMack, S., Tao, W.-K., Tompkins, A. M., Vane, D. G., Walker, C., and $\mathrm{Wu}, \mathrm{D} .:$ Cloud ice: A climate model challenge with signs and expectations of progress, J. Geophys. Res., 114, D00A21, doi:10.1029/2008JD010015, 2009.
Warren, S. G., Hahn, C. J., London, J., Chevin, R. M., and Jenne, R. L.: Global distribution of total cloud cover and cloud type amounts over land, NCAR Tech. Note TN-273+STR, National Center for Atmospheric Research, Boulder, Colorado, US, 1986.

Warren, S. G., Hahn, C. J., London, J., Chevin, R. M., and Jenne, R. L.: Global distribution of total cloud cover and cloud type amounts over ocean, NCAR Tech. Note TN-273+STR, National Center for Atmospheric Research, Boulder, Colorado, US, 1988.

Weng, F. Z. and Grody, N. C.: Retrieval of cloud liquid water using the Special Sensor Microwave Imager (SSM/I), J. Geophys. Res., 99, 25535-25551, 1994.

Xie, P. and Arkin, P. A.: Global precipitation: A 17-year monthly analysis based on gauge observations, satellite estimates, and numerical model outputs, B. Am. Meteorol. Soc., 78, 2539-2558, 1997.

Xue, H. and Feingold, G.: Large eddy simulations of tradewind cumuli: Investigation of aerosol indirect effects, J. Atmos. Sci., 63, 1605-1622, 2006.

Zhang, Y. C., Rossow, W. B., Lacis, A. A., Oinas, V., and Mishchenko, M. I.: Calculation of radiative fluxes from the surface to top of atmosphere based on ISCCP and other global data sets: Refinements of the radiative transfer model and the input data, J. Geophys. Res., 109, D19105, doi:10.1029/2003JD004457, 2004. 